Supplement of Hydrol. Earth Syst. Sci., 21, 6275-6288, 2017

https://doi.org/10.5194/hess-21-6275-2017-supplement

(c) Author(s) 2017. This work is distributed under

the Creative Commons Attribution 4.0 License.

(c) (1)

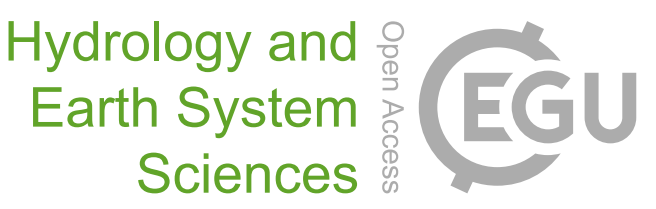

Supplement of

\title{
A coupled modeling framework for sustainable watershed management in transboundary river basins
}

Hassaan Furqan Khan et al.

Correspondence to: Y. C. Ethan Yang (yey217@lehigh.edu)

The copyright of individual parts of the supplement might differ from the CC BY 4.0 License. 


\section{S1 Review of ABM applications}

Table S1: Selected relevant existing studies of ABM applications in surface water management and ecological modeling

\begin{tabular}{|c|c|c|c|c|c|c|c|}
\hline Topics & Literature & Agent types & Agents' decisions & Agents' goal & $\begin{array}{c}\text { Hierarchical } \\
\text { agents }\end{array}$ & $\begin{array}{l}\text { Direct agent } \\
\text { interaction }\end{array}$ & $\begin{array}{c}\text { Link with } \\
\text { other models }\end{array}$ \\
\hline \multirow{14}{*}{ 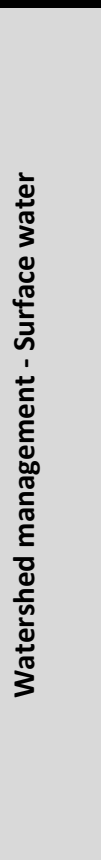 } & Barreteau et al. (2004) & farmers & farm activities & $\begin{array}{c}\text { simulate cultivating } \\
\text { activities }\end{array}$ & Yes & Yes & No \\
\hline & Berger et al. (2007) & water users & bid on land/water resources & max incomes & No & Yes & $\begin{array}{c}\text { Yes - } \\
\text { hydrological } \\
\text { model }\end{array}$ \\
\hline & Brady et al. (2012) & farmers & farm activities & max incomes & No & Yes & No \\
\hline & Farolfi et al. (2010) & farms/villages & water demand & simulate water demand & No & No & No \\
\hline & Giacomoni et al. (2013) & consumers/policy makers & water use/water restrict & simulate water demand & Yes & Yes & Yes - SWAT \\
\hline & Giuliani and Castelletti (2013) & reservoirs/delta & reservoir operation & $\begin{array}{l}\text { max HP/delta } \\
\text { preservation }\end{array}$ & No & Yes & No \\
\hline & Giuliani et al. (2015) & farm/city & water use & max profit & No & No & No \\
\hline & Jeuland et al. (2014) & reservoirs & reservoir operation & max profit & No & No & No \\
\hline & Kanta and Zechman (2014) & households/policy makers & conservation action/policy & simulate water demand & Yes & Yes & No \\
\hline & Ng et al. (2011) & farmers & crop/BMP choices & max profit & No & No & Yes - SWAT \\
\hline & Schluter et al. (2009) & farmers/lake/policy makers & water use & max profit & Yes & Yes & No \\
\hline & Schwarz and Ernst (2009) & households & $\begin{array}{l}\text { adoption of new water-related } \\
\text { technology }\end{array}$ & $\begin{array}{c}\text { simulate technology } \\
\text { diffusion }\end{array}$ & No & Yes & No \\
\hline & Yang et al. (2009) & farm/city & water use & $\begin{array}{l}\text { max profit } / \mathrm{min} \\
\text { violation }\end{array}$ & No & No & No \\
\hline & Yang et al. (2011) & subbasins & water use/water trading & max profit & No & Yes & No \\
\hline \multirow{3}{*}{ 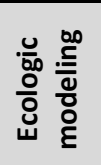 } & Bagstad et al., (2013) & carriers/sink/users of ES & carry/affect/use ES & simulate ES flow path & No & Yes & No \\
\hline & Miller et al. (2014) & waterfowls & $\begin{array}{l}\text { search food in foraging } \\
\text { patches }\end{array}$ & $\begin{array}{l}\text { simulate different } \\
\text { impact on foraging }\end{array}$ & No & No & No \\
\hline & Sun and Müller (2013) & farms & land use/land conservation & max profit & No & Yes & No \\
\hline
\end{tabular}




\section{S2 SWAT model setup}

The data used to set up the SWAT models for the two study river basins are shown in Table S2. SWAT is a semi-distributed model. In model setup, the Mekong River Basin is partitioned into 289 subbasins (Fig. S1(a)), and the Niger River Basin is divided into 178 subbasins (Fig. S1(b)). Hydrological response units (HRUs) were defined within subbasins to reflect the spatial variability of land use/land cover and soil. For this study, we defined crop HRUs for rainfed and irrigated upland crops and rice. The initial size of crop HRUs was estimated using cropping area data from International Food Policy Research Institute (IFPRI)'s SPAM database (You et al., 2014), which disaggregates national/sub-national crop production stations to a 5 arc minute grid.

The SWAT models contain customized modules to simulate storage and water surface variations of two major natural water impoundments: the Tonlé Sap in the Mekong River Basin and the Inner Niger Delta in the Niger River Basin. The storage variations of the Tonlé Sap and the Inner Niger Delta were modeled by following the approaches by Kirby et al. (2006) and Thompson et al.(2016), in which statistical relationships were developed to relate the outflow of the Tonlé Sap to streamflows at Kratie and outflow of the Inner Niger Delta at Diré to flows at Ké-Macina and Bénény Kégny. The water surface areas of the two water impoundments were further calculated using volume-surface relationship developed by Manley (2015) and Ogilvie (2017, personal communication).

Table S2: Data for SWAT model setup

\begin{tabular}{ll}
\hline Category & \multicolumn{1}{c}{ Data } \\
\hline Elevation & HydroSHEDS $^{1}$ \\
\hline Land use/land cover & GLC2000 $^{2}$ SPAM $2005^{3}$ \\
\hline Soil & Soil Map of the World \\
\hline Precipitation & $\begin{array}{l}\text { Mekong: APHRODITE } \\
\text { Niger: NCEP-CFSR }\end{array}$ \\
& using monthly precipitation data in CRU TS v. 4.00 ${ }^{7}$ ) \\
\hline $\begin{array}{l}\text { Temperatures/solar radiation/relative } \\
\text { humidity/wind speed }\end{array}$ & NCEP-CFSR \\
\hline
\end{tabular}

1. Source: The SHuttle Elevation Derivatives at multiple Scales (HydroSHEDS) database http://www.hydrosheds.org/

2. Source: Global Land Cover (GLC) 2000 database. European Commission, Joint Research Centre. http://forobs.jrc.ec.europa.eu/products/glc2000/glc2000.php

3. Source: Spatial Production Allocation Model (SPAM) database for 2005, IFPRI. http://mapspam.info/

4. Source: FAO/UNESCO. http://www.fao.org/soils-portal/soil-survey/soil-maps-anddatabases/faounesco-soil-map-of-the-world/en/

5. Source: Asian Precipitation-Highly Resolved Observational Data Integration Towards the Evaluation of Water Resources (APHRODITE) project. http://www.chikyu.ac.jp/precip/english/conditions.html

6. Source: National Centers for Environmental Prediction (NCEP) Climate Forecast System Reanalysis (CFSR); downloaded via global weather database for SWAT https://globalweather.tamu.edu/

7. Source: Climatic Research Unit - University of East Anglia. http://www.cru.uea.ac.uk/data 


\section{S3 Sub-basin Delineation}

(a) Mekong

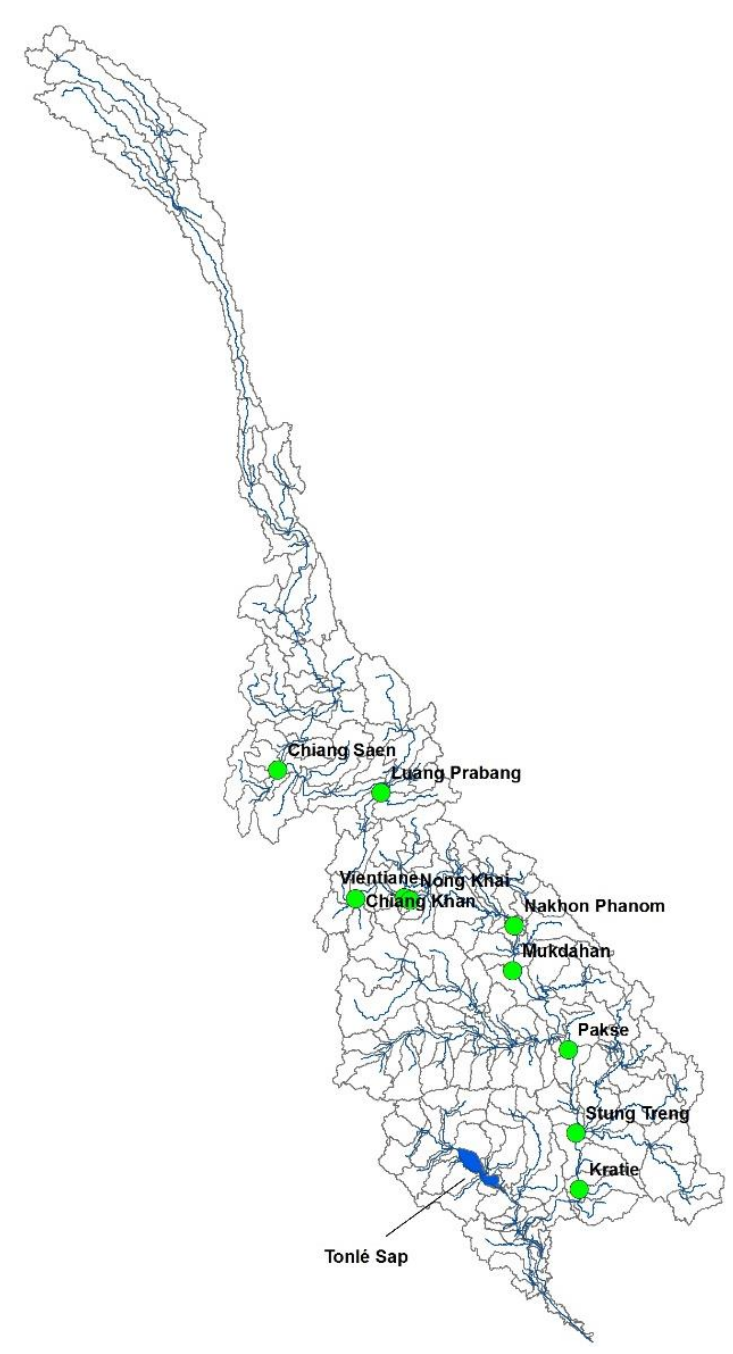

(b) Niger

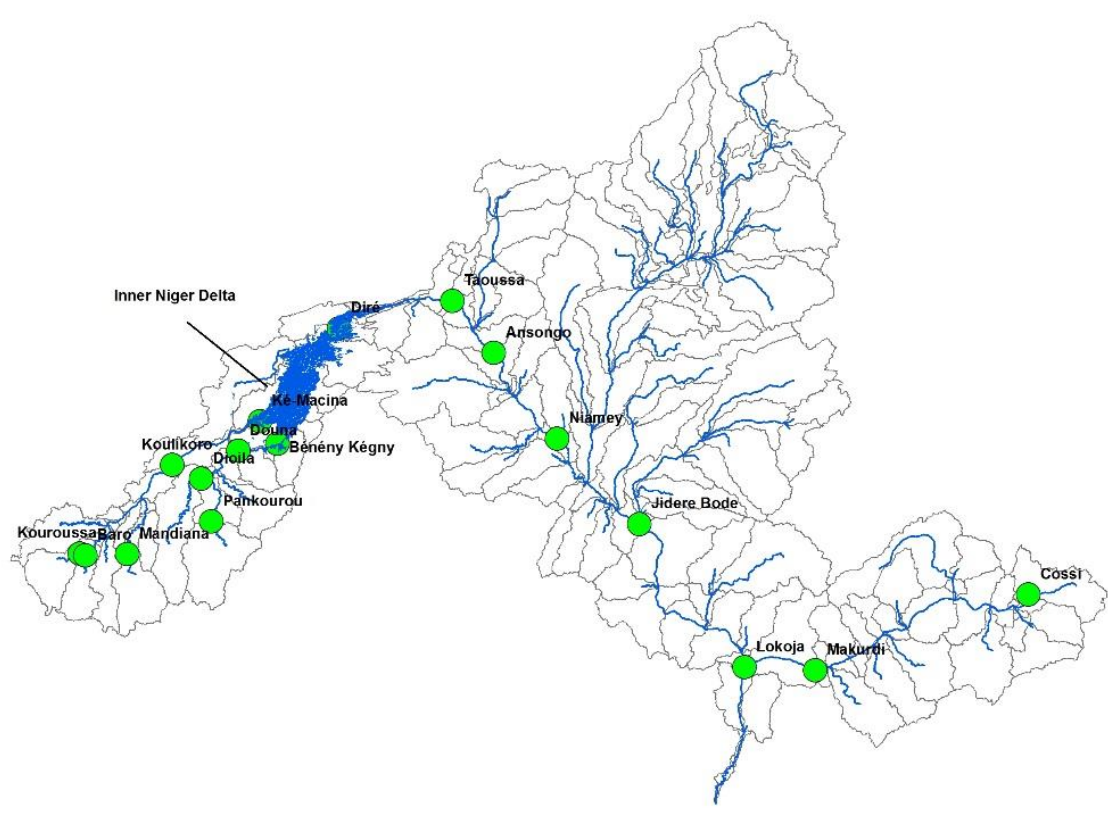

Figure S1 Watershed delineation schemes and locations of streamflow stations used in model calibration/validation 


\section{S4 Model Calibration and Validation}

The SWAT-Mekong model was calibrated and validated using daily streamflow data from 10 gauging stations, while for the Niger River basin, model calibration and validation was conducted on a monthly basis. The data were obtained from L'Institut de recherche pour le développement (IRD), Niger Basin Authority (NBA) and Global Runoff Data Centre (GRDC). The calibration/validation periods and the model fits achieved by the SWAT model in both case studies are shown in Figures S2 and S3, and Table S3 (a) and (b).

Table S3: Nash-Sutcliffe model efficiency coefficient

\section{Mekong}

\begin{tabular}{lcc}
\hline Station & Calibration (1983-1992) & Validation (1993-2007) \\
\hline Chiang Saen & 0.51 & 0.62 \\
Luang Prabang & 0.73 & 0.80 \\
Chiang Khan & 0.70 & 0.82 \\
Vientiane & 0.71 & 0.82 \\
Nong Khai & 0.74 & 0.82 \\
Nakhon Phanom & 0.80 & 0.84 \\
Mukdahan & 0.85 & 0.84 \\
Pakse & 0.82 & 0.85 \\
Stung Treng & 0.82 & 0.84 \\
Kratie & 0.83 & 0.85 \\
\hline
\end{tabular}

\section{Niger}

\begin{tabular}{lcc}
\hline Station & Calibration (1985-1994) & Validation (1995-2010) \\
\hline Ansongo & 0.88 & 0.50 \\
Baro & 0.80 & 0.33 \\
Beneny Kegny & 0.68 & 0.73 \\
Cossi & 0.81 & 0.08 \\
Dioila & 0.71 & 0.67 \\
Dire & 0.87 & 0.83 \\
Douna & 0.73 & 0.81 \\
Jidere Bode & 0.89 & 0.72 \\
Koulikoro & 0.92 & 0.72 \\
Kouroussa & 0.81 & 0.40 \\
Ke Macina & 0.88 & 0.66 \\
Lokoja & 0.86 & 0.72 \\
Makurdi & 0.81 & 0.87 \\
Mandiana & 0.65 & 0.42 \\
Niamey & 0.80 & 0.28 \\
Pankourou & 0.35 & 0.68 \\
Taoussa & 0.85 & 0.40 \\
\hline
\end{tabular}



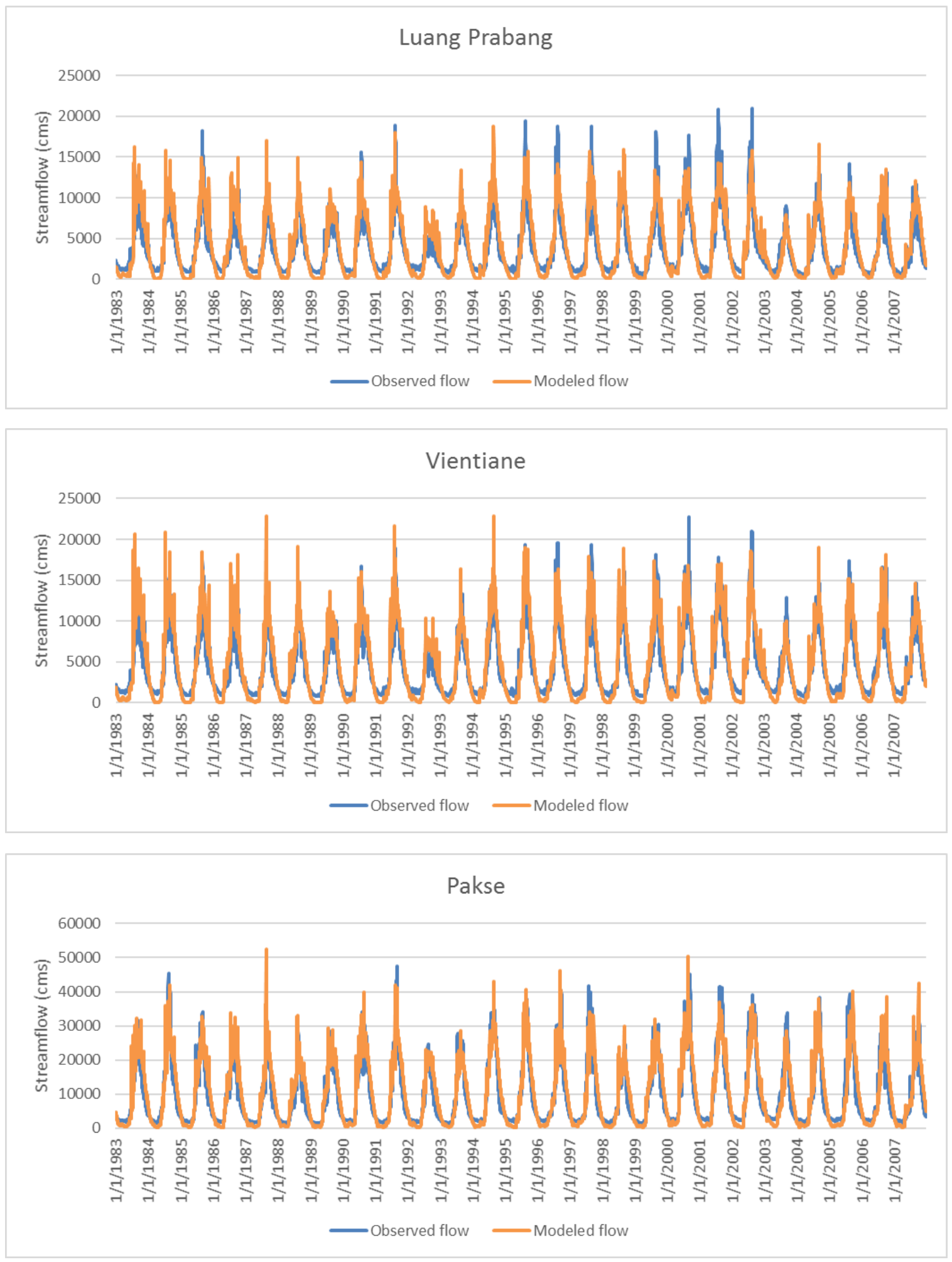

Figure S2: Simulated and observed streamflow at different locations along the Mekong River 

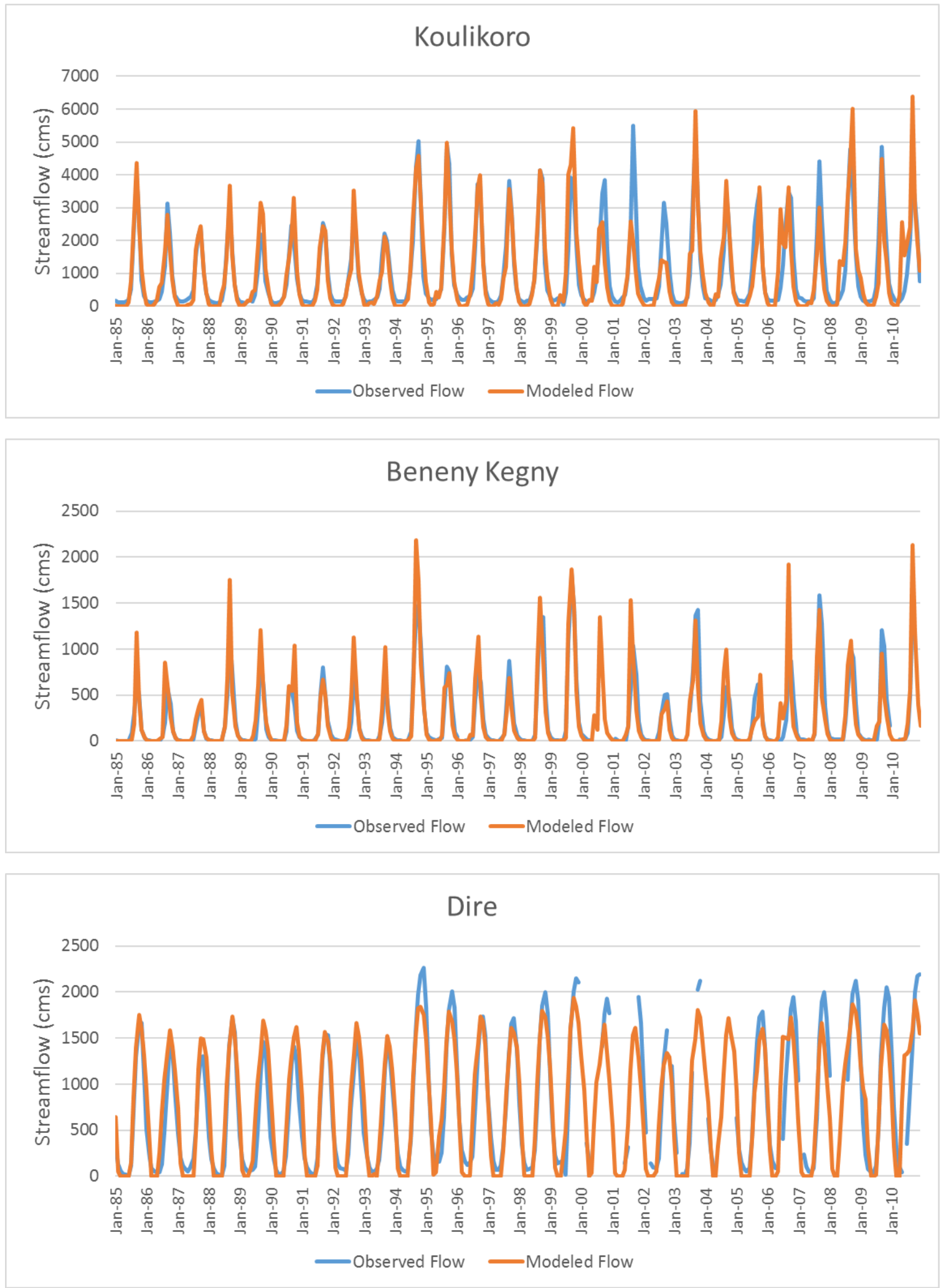

Figure S3: Simulated and observed streamflow at different locations along the Niger River 


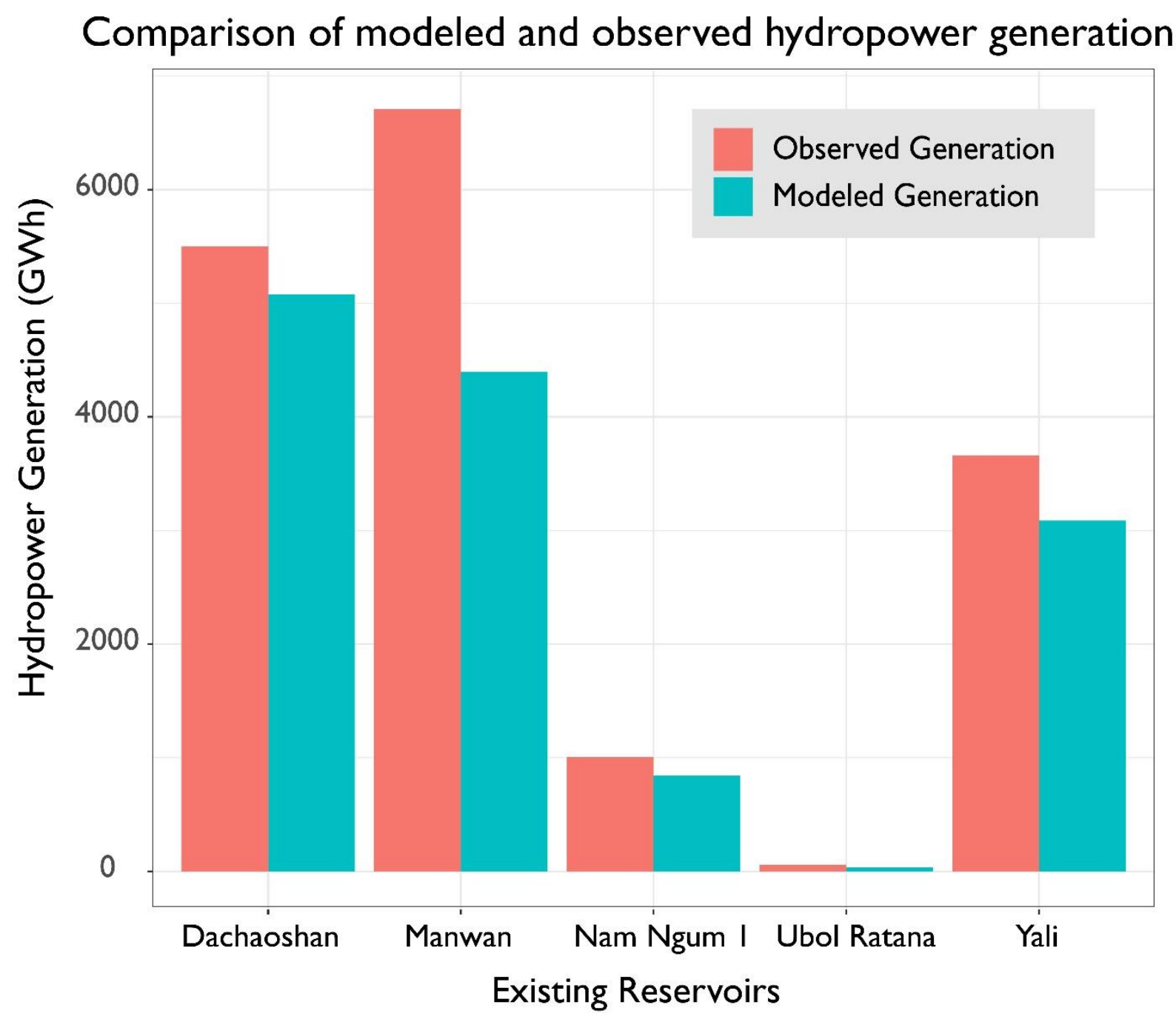

Figure S4: Comparison of simulated hydropower generated using the SWAT module under historic streamflow with observed generation in the Mekong River Basin 
S5 Survey questionnaire used to elicit water use preferences 


\section{River Basin Modeling for Ecosystem Services in the Niger}

Survey Introduction

The CGIAR Research Program on Water, Land and Ecosystems (WLE) in conjunction with the International Food Policy Research Institute (IFPRI) and partners is promoting a new approach to sustainable intensification in which healthy functioning ecosystems are seen as a prerequisite to agricultural development, food security and human well-being. Many of these ecosystems are water-based or water-related, and water-related ecosystems are also those most threatened by both human interventions and climate change.

Current water planning models are not equipped to adequately assess the interactions of ecosystems and economic development. If ecosystems are considered at all in these models, they are generally relegated to minimum flow constraints. In this project, we will define key water and related ecosystem services as active agents in a basin modeling approach. The project is implemented with core partners University of Massachusetts Amherst, the University of Illinois Urbana-Champaign, Wetlands International, WorldFish and L'Institut de recherche pour le développement (IRD), as well as national and regional partners.

Ecosystem services are defined as the benefits that ecosystems provide for humans. The basins selected for this study are the Indus, Mekong and Niger River Basins. With this e-survey, we solicit input on the ecosystem services of key importance in the various sub-regions of the Niger River Basin. This survey will focus on ecosystem services that are flow regime-dependent.

The survey will take approximately $\mathbf{2 0}$ minutes to complete. You do not need to fill in all questions and you can leave the survey at any time. We very much appreciate your help and support. As an incentive to fill in the survey, we will give away one iPad by lottery among those respondents who provide their contact information.

For any questions, please contact Claudia Ringler at c.ringler@cgiar.org or Simone Passarelli at s.passarelli@cgiar.org 


\section{River Basin Modeling for Ecosystem Services in the Niger}

1. Which of the following best describes the organization for which you work?

\section{Private company}

Government agency

Academic or other research institution

International non-governmental organization

Local non-governmental organization

Local/regional organization or coalition

Other (please specify)

2. If willing, please provide your job title.

3. If willing, please provide the name of the organization for which you work. 
4. Please select the country/countries in the Niger River Basin that you are currently focusing on (choose all that apply).

Guinea
$\square$ Côte d'Ivoire
$\square$ Bali
Burkina Faso
Algeria
Chad
Cameroon
Niger
$\square$ Benin

5. Is your work focused at an international level, national level, regional level, or district level (can select several)?

International

National

Regional (within one country)

Regional (across several countries)

District

Other (please specify) 
6. In which sector do you currently work (can select several)?

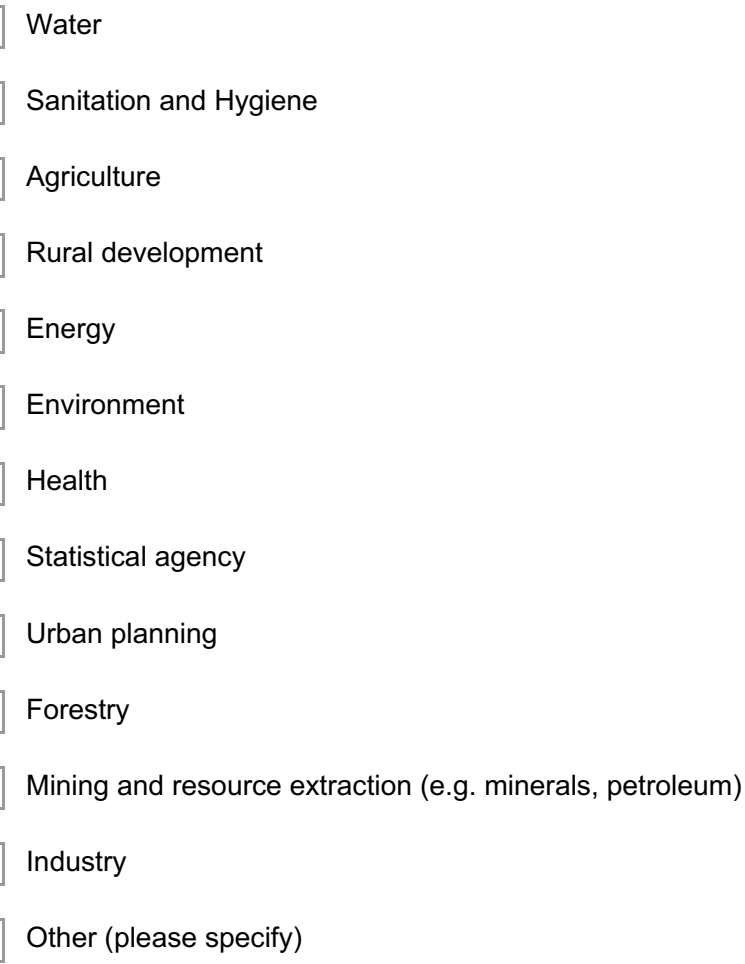

7. Which of the following categories best describes the majority of your duties, i.e. more than $50 \%$ of your work?

\section{Program/project management}

Technical specialist

Governance

Other (please specify) 


\section{River Basin Modeling for Ecosystem Services in the Niger}

8. Of the following 12 areas, please select the 3 that are most relevant to your current work.

Crop production

Livestock production

Fisheries and/or aquaculture

Energy production/management

Water, e.g. hydrology, hydrodynamics and hydraulics

Conservation, e.g. biodiversity and protected areas

Climate, e.g. temperature and precipitation

Ecology, e.g. water quality, sedimentation and fish species populations

Socioeconomic variables, e.g. income, occupation, welfare

Gender-focused research, e.g. sex-disaggregated data on time, health, welfare

Health, e.g. disease, mortality

Macroeconomic policies

Governance, including law and/or policy 
9. Please rank the following 13 areas based on their importance for environmental sustainability in your geographic area of focus, in your opinion, with \#1 being the most important (rank all 13 areas by selecting the appropriate number in the box to the left of each option).

\begin{tabular}{|c|c|c|}
\hline i: & $\hat{\nabla}$ & Crop production \\
\hline i: & $\hat{\nabla}$ & Livestock production \\
\hline$\because ;$ & $\hat{\boldsymbol{\theta}}$ & Fisheries and/or aquaculture \\
\hline : $;$ & $\hat{\nabla}$ & Energy production/management \\
\hline$\because$ & $\hat{\nabla}$ & Water, e.g. hydrology, hydrodynamics and hydraulics \\
\hline : & $\hat{\boldsymbol{\Delta}}$ & Conservation, e.g. biodiversity and protected areas \\
\hline ;: & $\hat{\nabla}$ & Climate, e.g. temperature and precipitation \\
\hline$\ddot{*}$ & $\hat{\nabla}$ & Ecology, e.g. water quality, sedimentation and fish species populations \\
\hline : $:$ & $\hat{\nabla}$ & Socioeconomic variables, e.g. income, occupation, welfare \\
\hline : & $\hat{\nabla}$ & Gender-focused research, e.g. sex-disaggregated data on time, health, welfare \\
\hline i: & $\hat{\boldsymbol{\theta}}$ & Health, e.g. disease, mortality \\
\hline$\ddot{i}$ & $\hat{\nabla}$ & Macroeconomic policies \\
\hline$\because ;$ & $\hat{\nabla}$ & Governance, including law and/or policy \\
\hline
\end{tabular}

10. How often do you collaborate with other sectors for planning and/or decision-making purposes?

Often

Sometimes

Never

Not applicable 


\section{River Basin Modeling for Ecosystem Services in the Niger}

\section{Collaborating Agencies}

11. Please select the other sectors with which you collaborate for planning and/or decision-making.

Water

Sanitation and Hygiene

Agriculture

Rural development

Energy

Environment

Health

Statistical agency

Urban planning

Forestry

Mining and resource extraction (e.g. minerals, petroleum)

Industry

Other (please specify) 


\section{River Basin Modeling for Ecosystem Services in the Niger}

\section{Data Sources}

12. In your daily work, do you do any of the following (please select all that apply)?

Data collection

Use of primary data (data collected from scratch for your purposes)

Use of secondary data (data from an existing source)

None of the above

Other data applications (please specify)

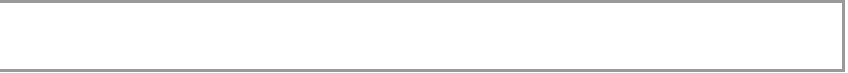

13. Which types of data do you use in your work (select all that apply)?

Crop production

Livestock production

Fisheries and/or aquaculture

Energy production/management

Water, e.g. hydrology, hydrodynamics and hydraulics

Conservation, e.g. biodiversity and protected areas

Climate, e.g. temperature and precipitation

Ecology, e.g. water quality, sedimentation and fish species populations

Socioeconomic variables, e.g. income, occupation, welfare

Gender-focused research, e.g. sex-disaggregated data on time, health, welfare

Health, e.g. disease, mortality

Macroeconomic policies

Governance, including law and/or policy

Not applicable to my work

Other (please specify) 
14. Please briefly describe the types of data that are most important to your work? E.g. local/national/international crop price/production data, water streamflow levels collected by your agency, etc.

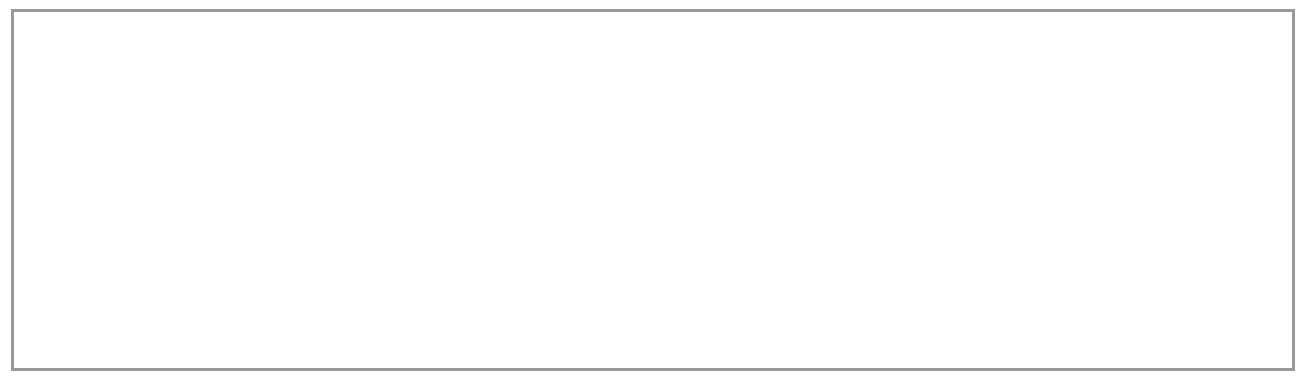

15. In which of the following areas do you find there are the greatest data gaps that limit your current work? (select all that apply)?

Crop production

Livestock production

Fisheries and/or aquaculture

Energy production/management

Water, e.g. hydrology, hydrodynamics and hydraulics

Conservation, e.g. biodiversity and protected areas

Climate, e.g. temperature and precipitation

Ecology, e.g. water quality, sedimentation and fish species populations

Socioeconomic variables, e.g. income, occupation, welfare

$\square$ Gender-focused research, e.g. sex-disaggregated data on time, health, welfare

Health, e.g. disease, mortality

Macroeconomic policies

Governance, including law and/or policy

Not applicable to my work

No gaps

$\square$ Other (please specify) 
16. If you find data gaps in your work, briefly describe the types of data that would be most useful to fill these gaps.

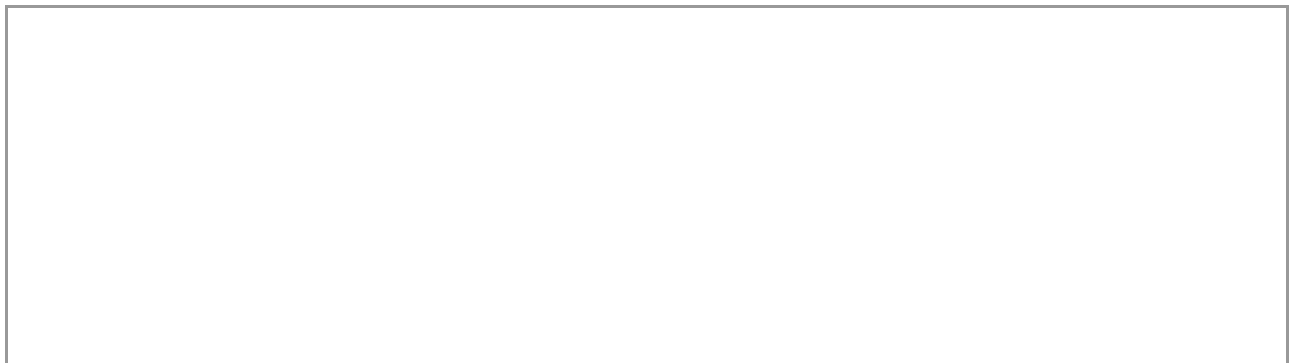

17. Do you use any gender variables when conducting your work?

Y Yes

No 


\section{River Basin Modeling for Ecosystem Services in the Niger}

Reasons for not using gender variables

18. Why do you not use gender variables in your work? 
River Basin Modeling for Ecosystem Services in the Niger

Use of Gender Variables

19. What kind of gender variables do you use in your work? 


\section{River Basin Modeling for Ecosystem Services in the Niger}

\section{Ecosystem Services and other related factors in the River Basin}

20. Which water-related ecosystem services, that is, services humans derive from ecosystems, and other elements are of key importance in the Niger River Basin? Please give percentage weights to those services that you find to be most important in this basin with the total adding to 100 .

Water for irrigated staples (e.g. rice, maize)

Water for irrigated cash crops (e.g. sugarcane)

Water for irrigated horticultural crops (e.g. vegetables, fruits)

Water for fiber

Water for energy (e.g. hydropower)

Water for domestic water supply

Water for industrial water supply

Navigation

Fisheries/aquaculture

Environmental flows to maintain water-based ecosystems

Water for important cultural purposes

Water to support protected areas

Water to support nature and other items of religious and cultural significance

Water for wetland uses (e.g. aquatic species, regulation of floods, regulation of water quality)

Control of sedimentation and soil erosion
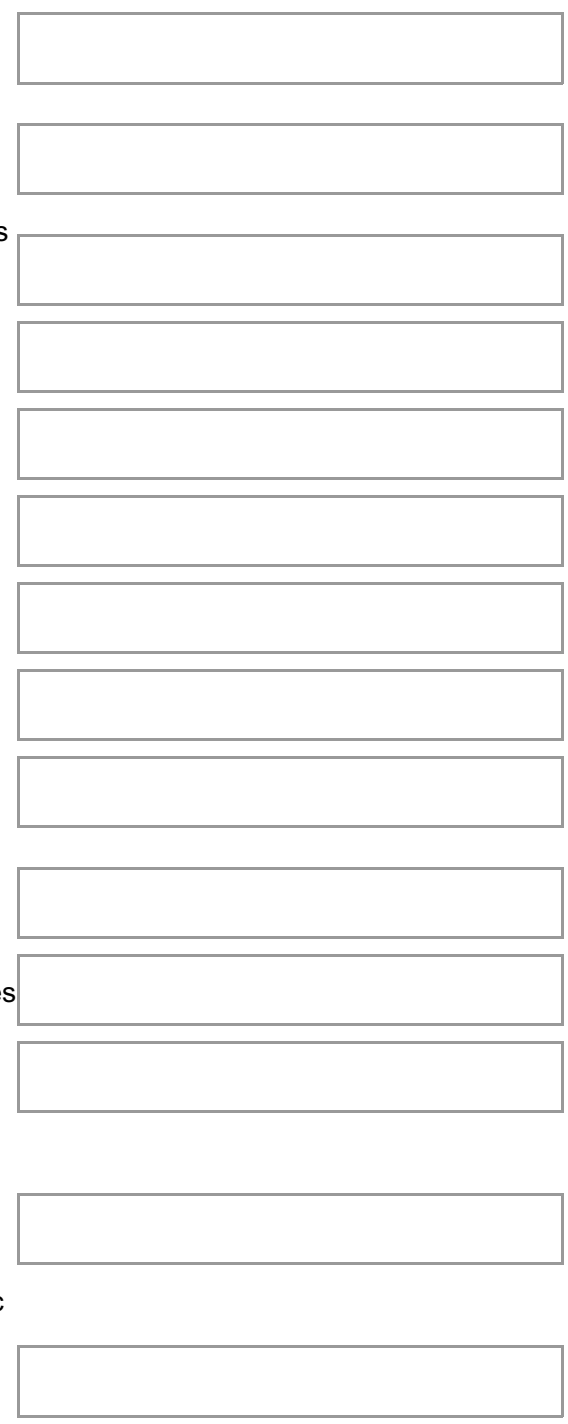
21. If the basin would get investments of US $\$ 100$ billion, which of the ecosystem services and other elements listed below would you want to see further developed or protected? Please give percentage weights to those services that you find to be most important to receive investments in this basin with the total adding to 100 .

Water for irrigated staples (e.g. rice, maize)

Water for irrigated cash crops (e.g. sugarcane)

Water for irrigated horticultural crops (e.g. vegetables fruits)

Water for fiber

Water for energy (e.g. hydropower)

Water for domestic water supply

Water for industrial water supply

Navigation

Fisheries/aquaculture

Environmental flows to maintain water-based ecosystems

Water for important cultural purposes

Water to support protected areas

Water to support nature and other items of religious and cultural significance

Water for wetland uses (e.g. aquatic species, regulation of floods, regulation of water quality)

Control of sedimentation and soil erosion
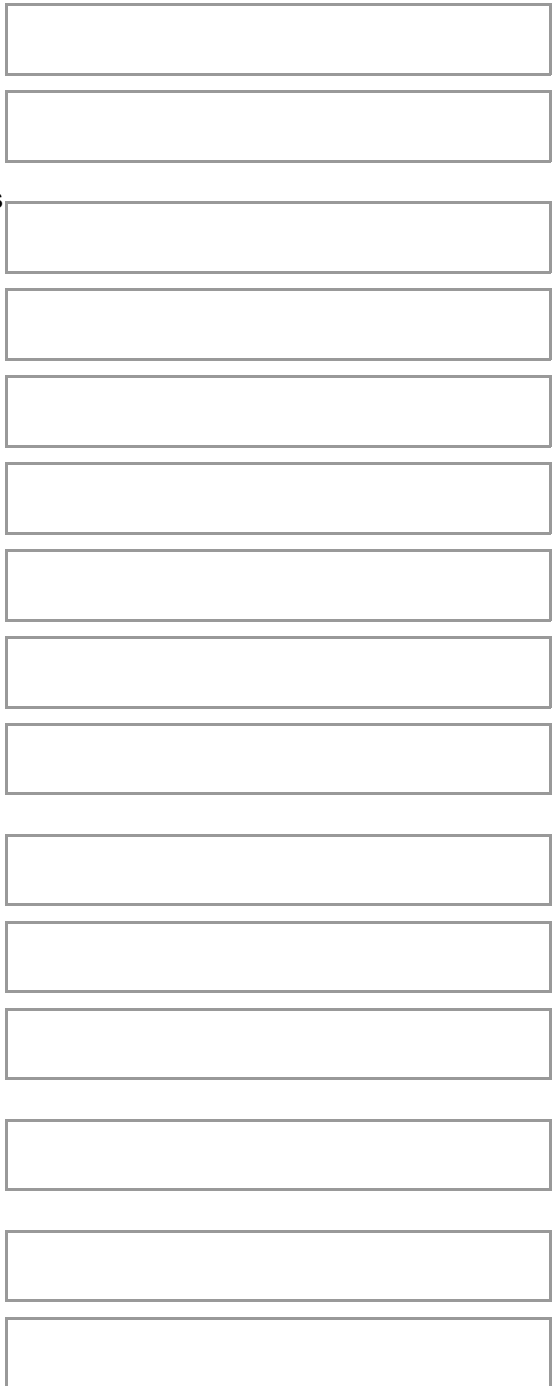
22. What would be your weights if the basin would experience a 3-year drought? Please give percentage weights to those services that you find to be most important under a severe drought in this basin with the total adding to 100 .

Water for irrigated staples (e.g. rice, maize)

Water for irrigated cash crops (e.g. sugarcane)

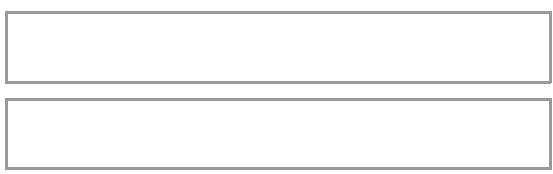

Water for irrigated horticultural crops (e.g. vegetables fruits)

Water for fiber

Water for energy (e.g. hydropower)

Water for domestic water supply

Water for industrial water supply

Navigation

Fisheries/aquaculture

Environmental flows to maintain water-based ecosystems

Water for important cultural purposes

Water to support protected areas

Water to support nature and other items of religious and cultural significance

Water for wetland uses (e.g. aquatic species, regulation of floods, regulation of water quality)

Control of sedimentation and soil erosion
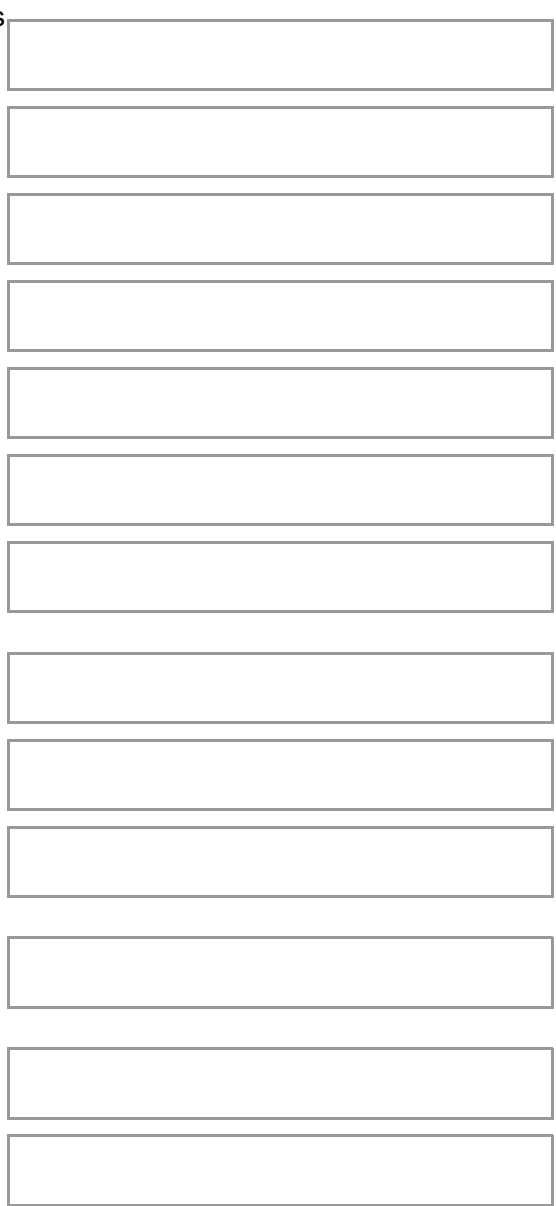
23. Which ecosystem services and other elements do you think will increase in quantity and quality in the next five years given current trends? Please give higher percentage weights to those services that you believe will improve most in the next five years in this basin with the total adding to 100 . You can enter 100 in the line "None" line if you believe that none will improve.

Water for irrigated staples (e.g. rice, maize)

Water for irrigated cash crops (e.g. sugarcane)

Water for irrigated horticultural crops (e.g. vegetables fruits)

Water for fiber

Water for energy (e.g. hydropower)

Water for domestic water supply

Water for industrial water supply

Navigation

Fisheries/aquaculture

Environmental flows to maintain water-based ecosystems

Water for important cultural purposes

Water to support protected areas

Water to support nature and other items of religious and cultural significance

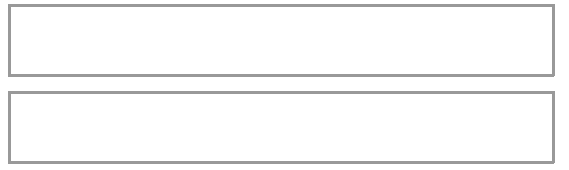

Water for wetland uses (e.g. aquatic species, regulation of floods, regulation of water quality)

Control of sedimentation and soil erosion
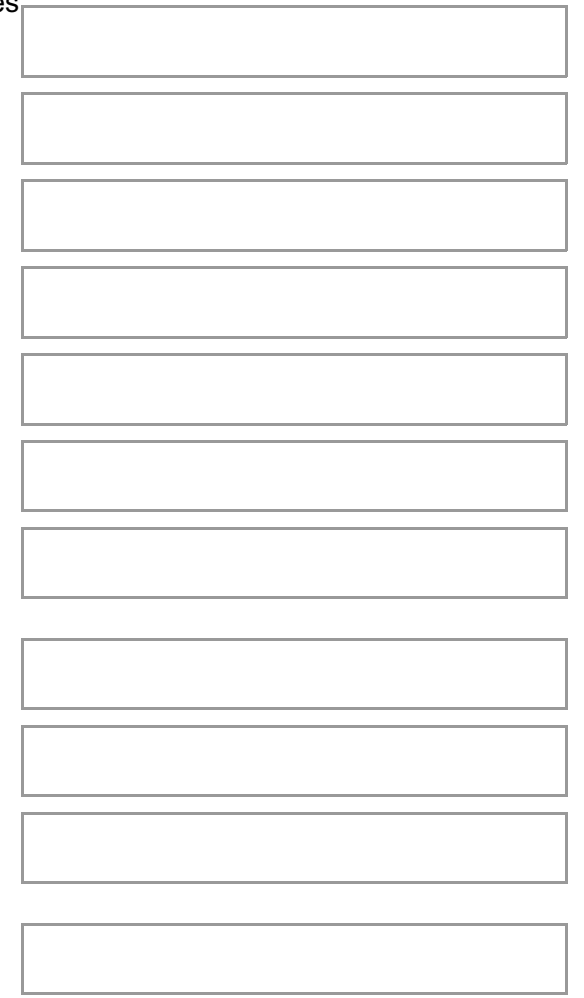

None

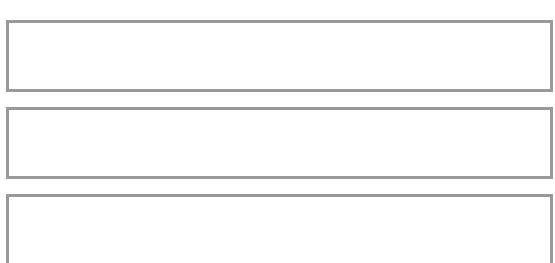


24. Which ecosystem services and other elements will likely decline in quantity and or quality in the next five years given current trends? Please give higher percentage weights to those services that you believe will decline most in the next five years in this basin with the total adding to 100 . You can enter 100 in the line "None" if you believe that none will decline.

Water for irrigated staples (e.g. rice, maize)

Water for irrigated cash crops (e.g. sugarcane)

Water for irrigated horticultural crops (e.g. vegetables fruits)

Water for fiber

Water for energy (e.g. hydropower)

Water for domestic water supply

Water for industrial water supply

Navigation

Fisheries/aquaculture

Environmental flows to maintain water-based ecosystems

Water for important cultural purposes

Water to support protected areas

Water to support nature and other items of religious and cultural significance

Water for wetland uses (e.g. aquatic species, regulation of floods, regulation of water quality)

Control of sedimentation and soil erosion
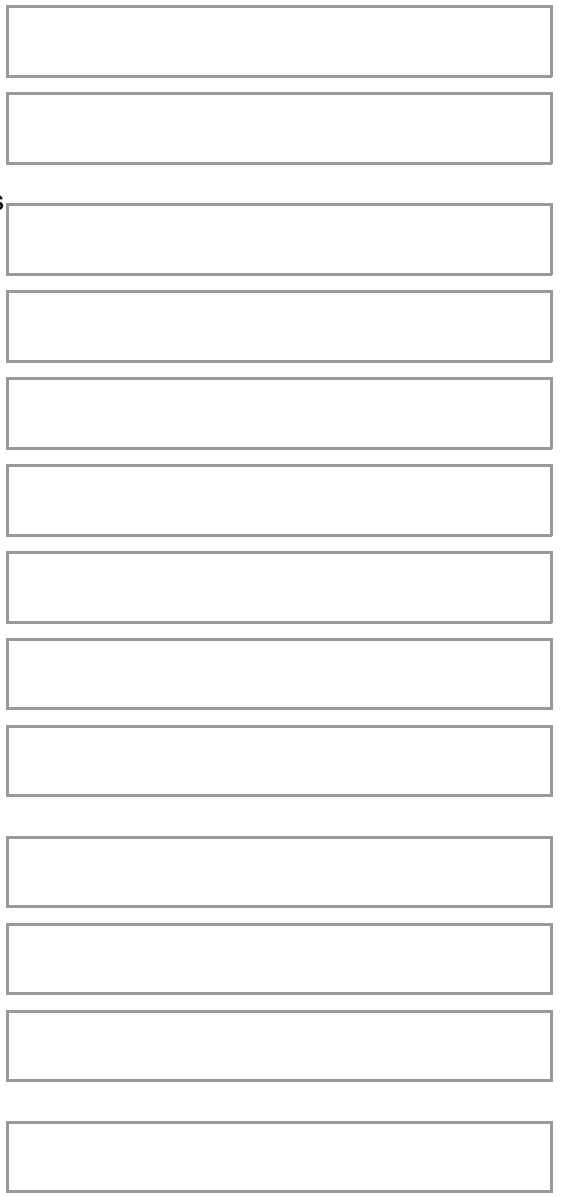

None

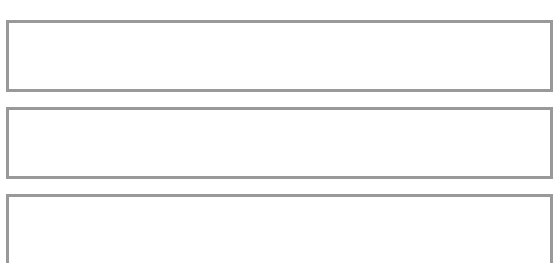




\section{River Basin Modeling for Ecosystem Services in the Niger}

Sub-regions of the Niger

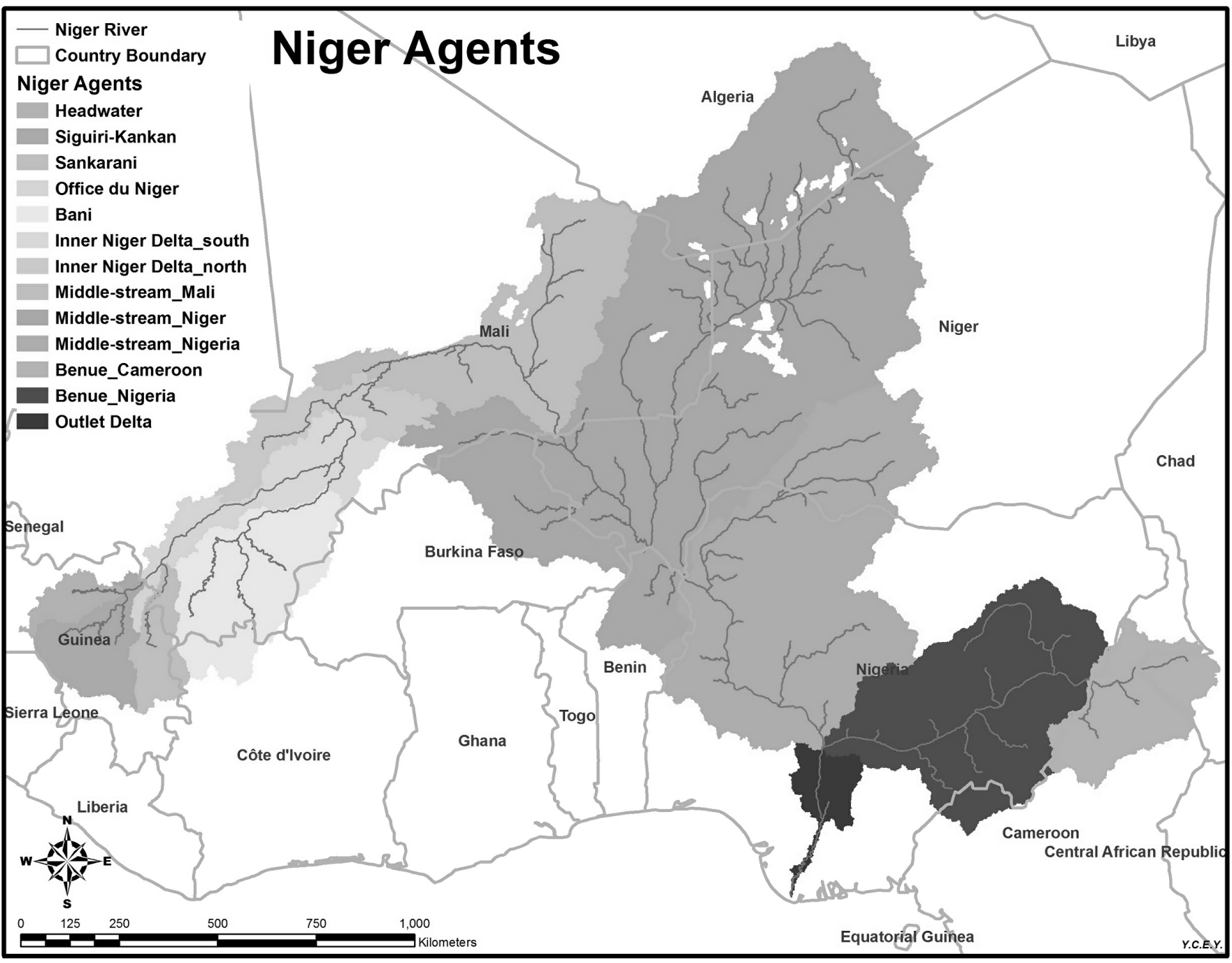

We have identified 13 sub-regions in the Niger River Basin. Please refer to the image above for the following questions. 
25. Which of these sub-regions would you consider to be a hotspot (a place of significant activity or danger) for ecosystems, such as wetlands, forests, species diversity and abundance, etc.)? Please give percentage weights to the areas you find to be most important in this basin with the total adding to 100 . Enter 100 in the line "None" if you believe that none are the largest hotspots.

Headwater

Siguiri-Kankan

Sankarani

Office du Niger

Bani

Inner Niger Delta, South

Inner Niger Delta, North

Middle-stream, Mali

Middle-stream, Niger

Middle-stream, Nigeria

Benue, Cameroon

Benue, Nigeria

Outlet Delta

None

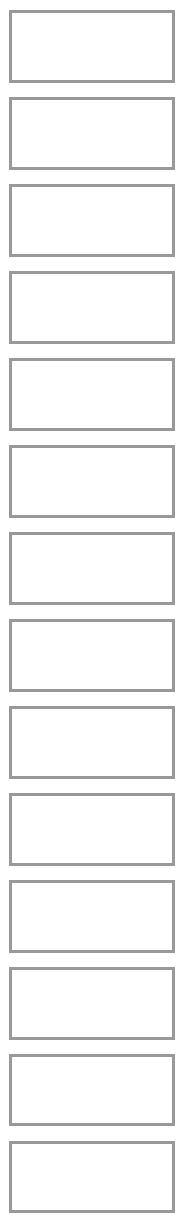


26. Which of these sub-regions do you think will improve the quality and/or quantity of its natural resources and ecosystems in the next 5 years? Please give percentage weights to the areas that you think are most likely to improve in this basin, with the total adding to 100 . Enter 100 in the line "None" if you believe that none will improve their quality and/or quantity.

Headwater

Siguiri-Kankan

Sankarani

Office du Niger

Bani

Inner Niger Delta, South

Inner Niger Delta, North

Middle-stream, Mali

Middle-stream, Niger

Middle-stream, Nigeria

Benue, Cameroon

Benue, Nigeria

Outlet Delta

None

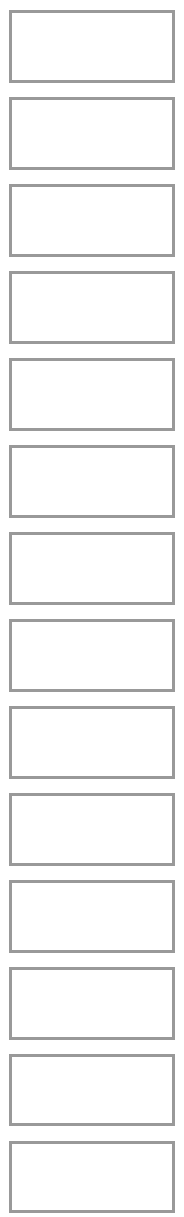

The following questions ask for a ranking of the same ecosystem services for each of the 13 key sub-regions used in this study. Please use the image above for reference when responding to the following questions. If you are unfamiliar with a specific sub-region, you do not need to answer questions about it. 


\section{Headwater}

Please give percentage weights to those services that you find to be most important in this sub-basin with the total adding to 100 .

Water for irrigated staples (e.g. rice, maize)

Water for irrigated cash crops (e.g. sugarcane)

Water for irrigated horticultural crops (e.g. vegetables fruits)

Water for fiber

Water for energy (e.g. hydropower)

Water for domestic water supply

Water for industrial water supply

Navigation

Fisheries/aquaculture

Environmental flows to maintain water-based ecosystems

Water for important cultural purposes

Water to support protected areas

Water to support nature and other items of religious and cultural significance

Water for wetland uses (e.g. aquatic species,

regulation of floods, regulation of water quality)

Control of sedimentation and soil erosion
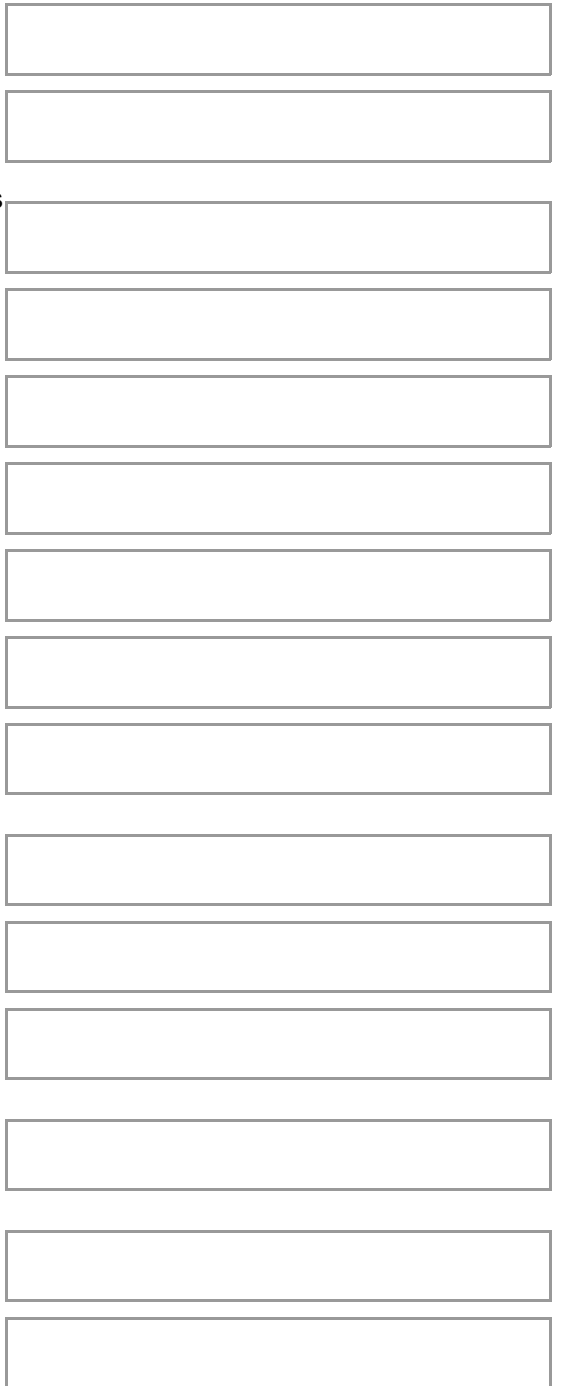


\section{Siguiri-Kankan}

Please give percentage weights to those services that you find to be most important in this sub-basin with the total adding to 100 .

Water for irrigated staples (e.g. rice, maize)

Water for irrigated cash crops (e.g. sugarcane)

Water for irrigated horticultural crops (e.g. vegetables fruits)

Water for fiber

Water for energy (e.g. hydropower)

Water for domestic water supply

Water for industrial water supply

Navigation

Fisheries/aquaculture

Environmental flows to maintain water-based ecosystems

Water for important cultural purposes

Water to support protected areas

Water to support nature and other items of religious and cultural significance

Water for wetland uses (e.g. aquatic species, regulation of floods, regulation of water quality)

Control of sedimentation and soil erosion
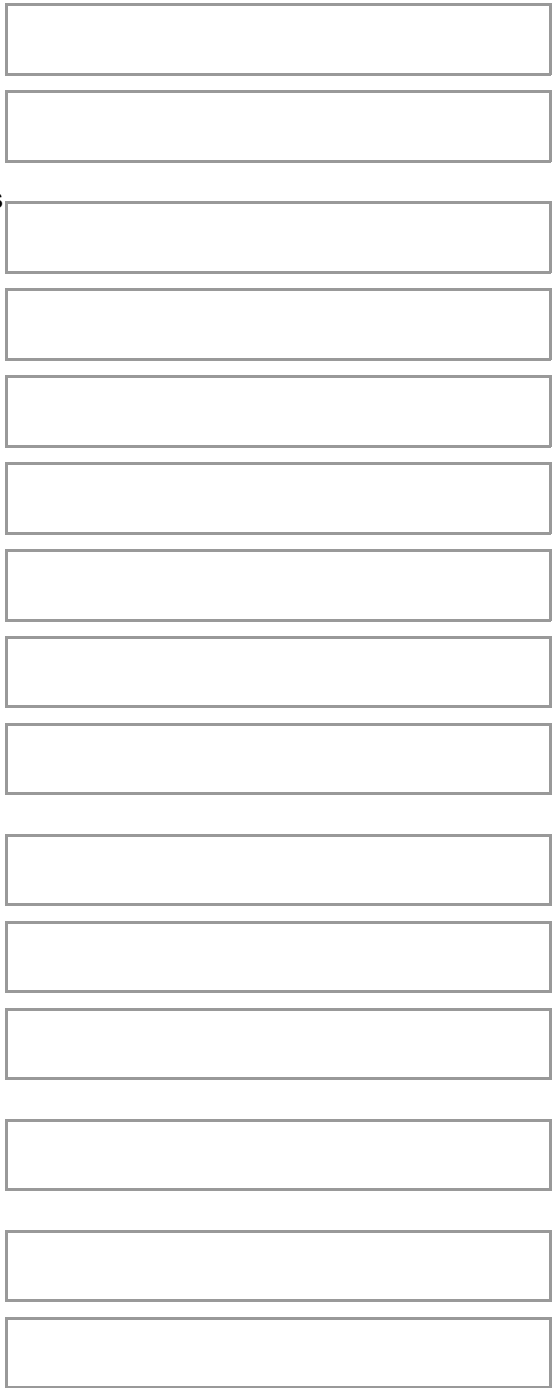


\section{Sankarani}

Please give percentage weights to those services that you find to be most important in this sub-basin with the total adding to 100 .

Water for irrigated staples (e.g. rice, maize)

Water for irrigated cash crops (e.g. sugarcane)

Water for irrigated horticultural crops (e.g. vegetables fruits)

Water for fiber

Water for energy (e.g. hydropower)

Water for domestic water supply

Water for industrial water supply

Navigation

Fisheries/aquaculture

Environmental flows to maintain water-based ecosystems

Water for important cultural purposes

Water to support protected areas

Water to support nature and other items of religious and cultural significance

Water for wetland uses (e.g. aquatic species,

regulation of floods, regulation of water quality)

Control of sedimentation and soil erosion
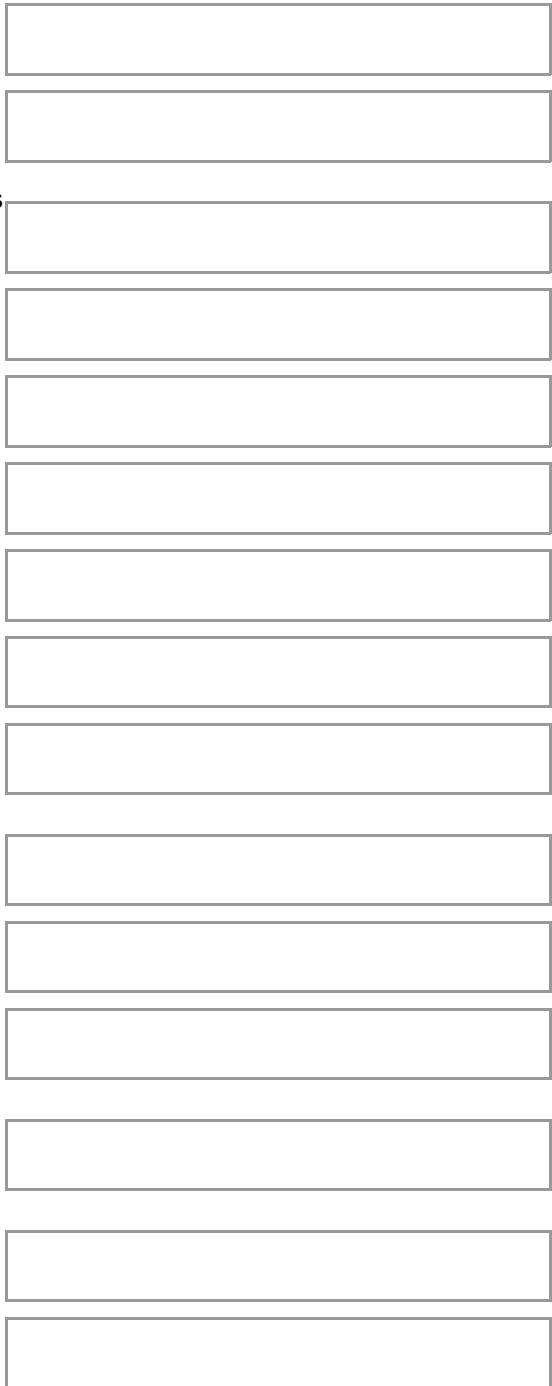


\section{0. $\underline{\text { Office du Niger }}$}

Please give percentage weights to those services that you find to be most important in this sub-basin with the total adding to 100 .

Water for irrigated staples (e.g. rice, maize)

Water for irrigated cash crops (e.g. sugarcane)

Water for irrigated horticultural crops (e.g. vegetables fruits)

Water for fiber

Water for energy (e.g. hydropower)

Water for domestic water supply

Water for industrial water supply

Navigation

Fisheries/aquaculture

Environmental flows to maintain water-based ecosystems

Water for important cultural purposes

Water to support protected areas

Water to support nature and other items of religious and cultural significance

Water for wetland uses (e.g. aquatic species,

regulation of floods, regulation of water quality)

Control of sedimentation and soil erosion
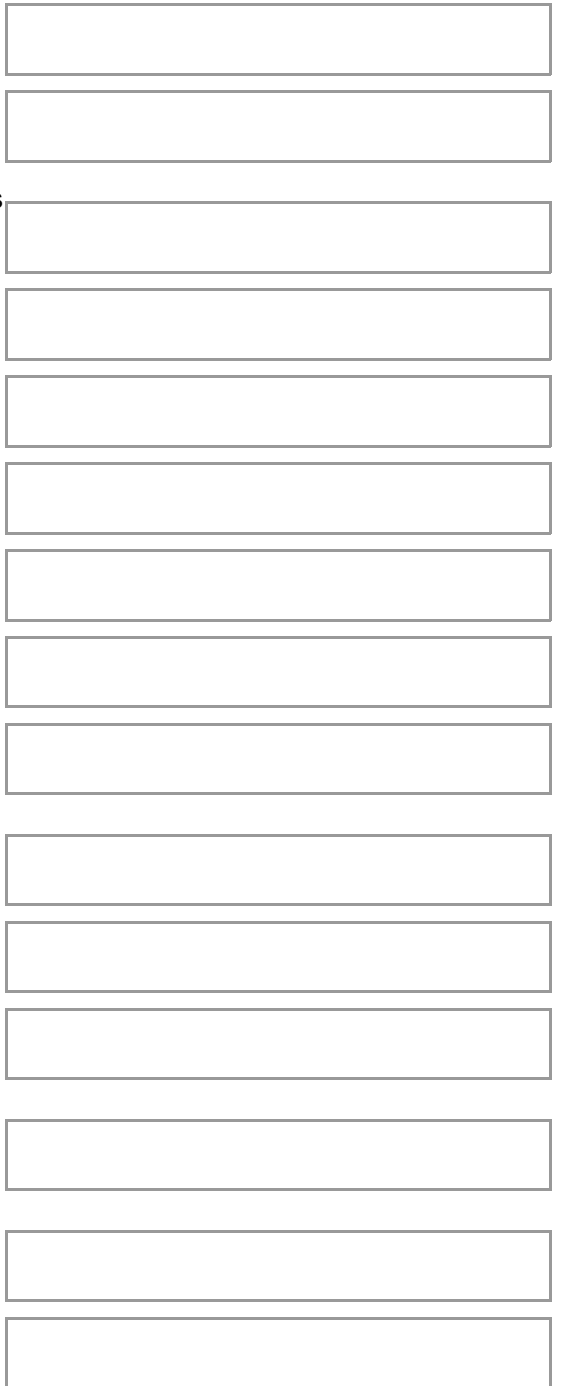


\section{Bani}

Please give percentage weights to those services that you find to be most important in this sub-basin with the total adding to 100 .

Water for irrigated staples (e.g. rice, maize)

Water for irrigated cash crops (e.g. sugarcane)

Water for irrigated horticultural crops (e.g. vegetables fruits)

Water for fiber

Water for energy (e.g. hydropower)

Water for domestic water supply

Water for industrial water supply

Navigation

Fisheries/aquaculture

Environmental flows to maintain water-based ecosystems

Water for important cultural purposes

Water to support protected areas

Water to support nature and other items of religious and cultural significance

Water for wetland uses (e.g. aquatic species,

regulation of floods, regulation of water quality)

Control of sedimentation and soil erosion
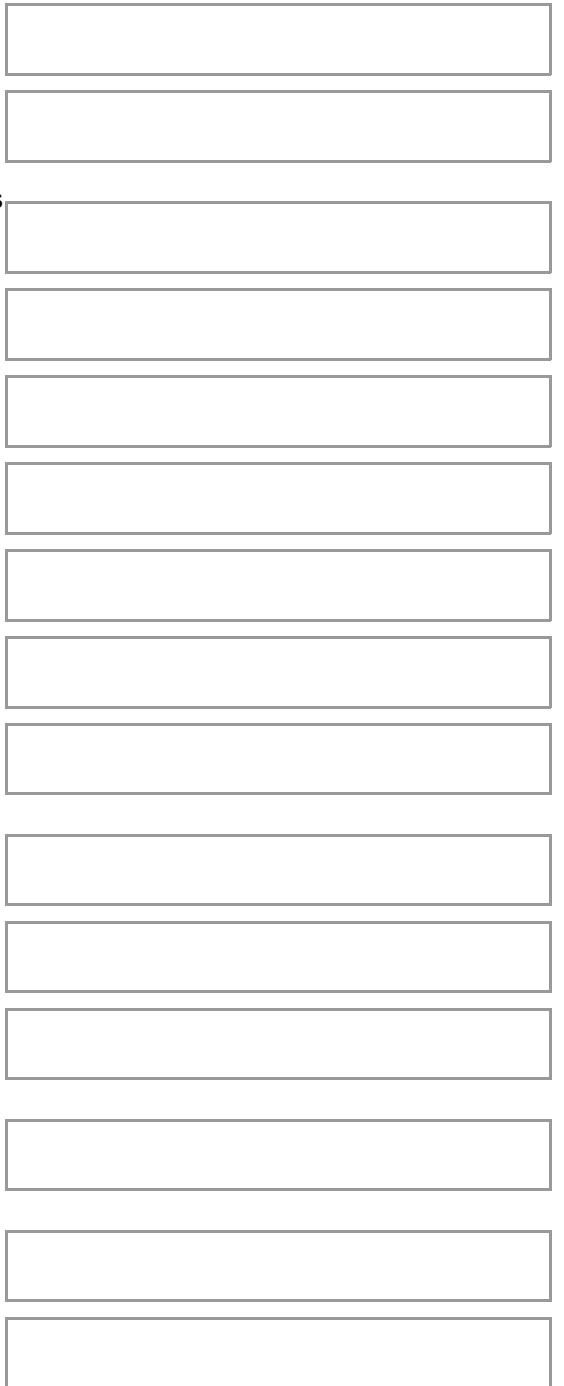


\section{Inner Niger Delta, South}

Please give percentage weights to those services that you find to be most important in this sub-basin with the total adding to 100 .

Water for irrigated staples (e.g. rice, maize)

Water for irrigated cash crops (e.g. sugarcane)

Water for irrigated horticultural crops (e.g. vegetables fruits)

Water for fiber

Water for energy (e.g. hydropower)

Water for domestic water supply

Water for industrial water supply

Navigation

Fisheries/aquaculture

Environmental flows to maintain water-based ecosystems

Water for important cultural purposes

Water to support protected areas

Water to support nature and other items of religious and cultural significance

Water for wetland uses (e.g. aquatic species, regulation of floods, regulation of water quality)

Control of sedimentation and soil erosion
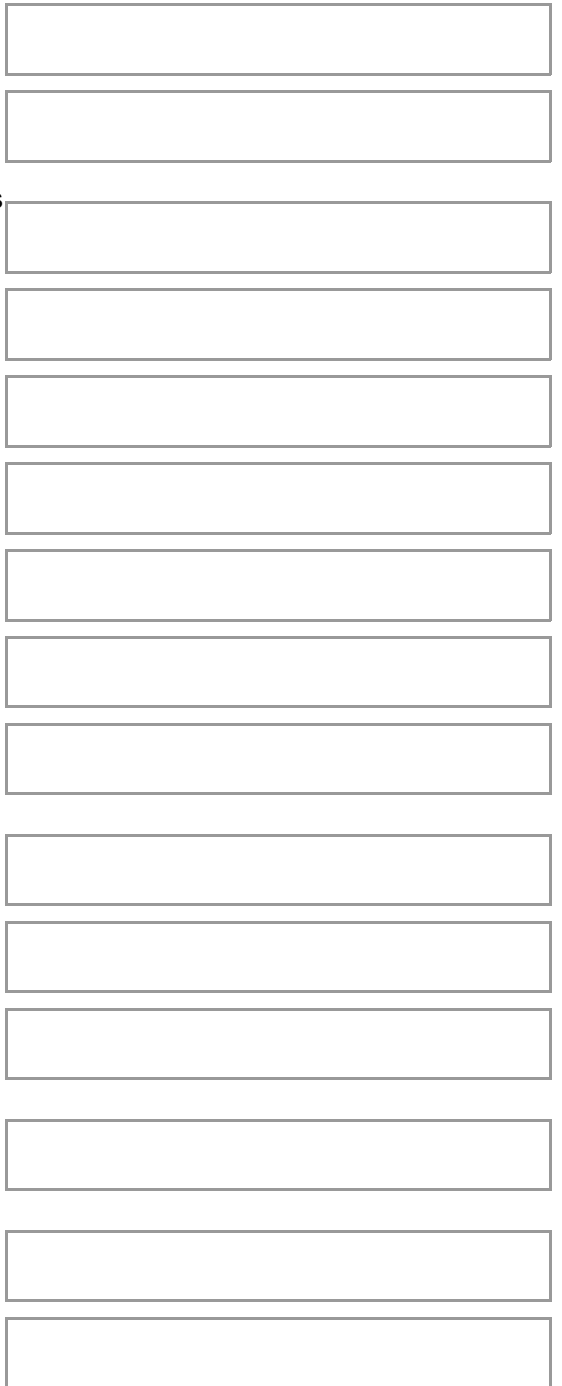


\section{Inner Niger Delta, North}

Please give percentage weights to those services that you find to be most important in this sub-basin with the total adding to 100 .

Water for irrigated staples (e.g. rice, maize)

Water for irrigated cash crops (e.g. sugarcane)

Water for irrigated horticultural crops (e.g. vegetables fruits)

Water for fiber

Water for energy (e.g. hydropower)

Water for domestic water supply

Water for industrial water supply

Navigation

Fisheries/aquaculture

Environmental flows to maintain water-based ecosystems

Water for important cultural purposes

Water to support protected areas

Water to support nature and other items of religious and cultural significance

Water for wetland uses (e.g. aquatic species, regulation of floods, regulation of water quality)

Control of sedimentation and soil erosion
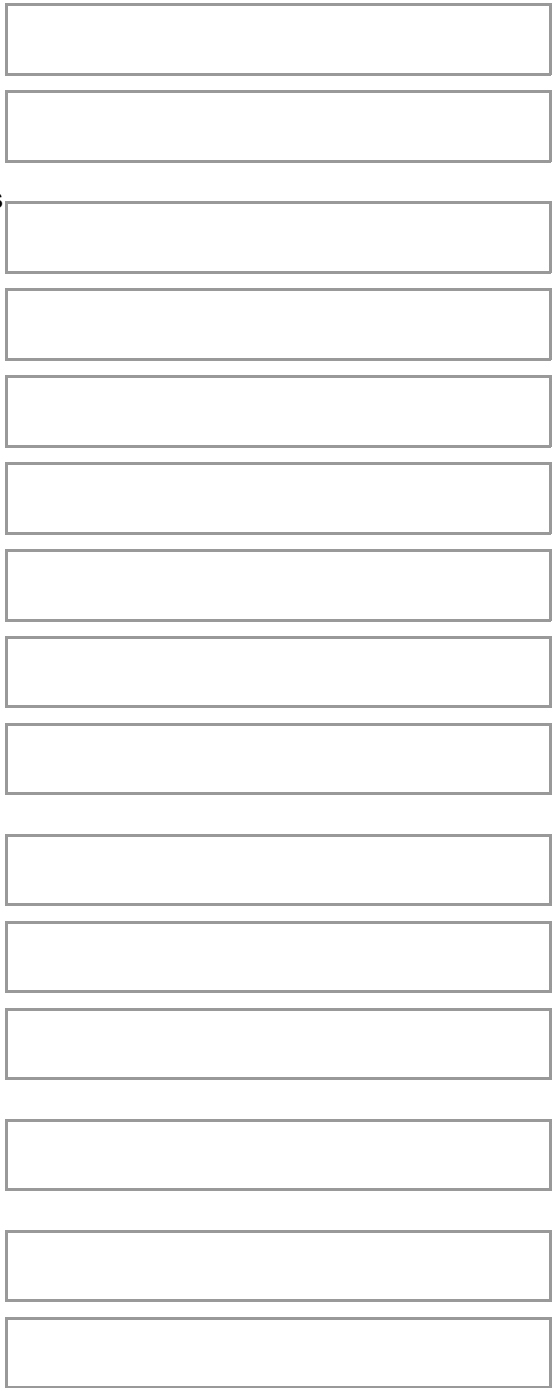


\section{Middle-stream, Mali}

Please give percentage weights to those services that you find to be most important in this sub-basin with the total adding to 100 .

Water for irrigated staples (e.g. rice, maize)

Water for irrigated cash crops (e.g. sugarcane)

Water for irrigated horticultural crops (e.g. vegetables fruits)

Water for fiber

Water for energy (e.g. hydropower)

Water for domestic water supply

Water for industrial water supply

Navigation

Fisheries/aquaculture

Environmental flows to maintain water-based ecosystems

Water for important cultural purposes

Water to support protected areas

Water to support nature and other items of religious and cultural significance

Water for wetland uses (e.g. aquatic species, regulation of floods, regulation of water quality)

Control of sedimentation and soil erosion
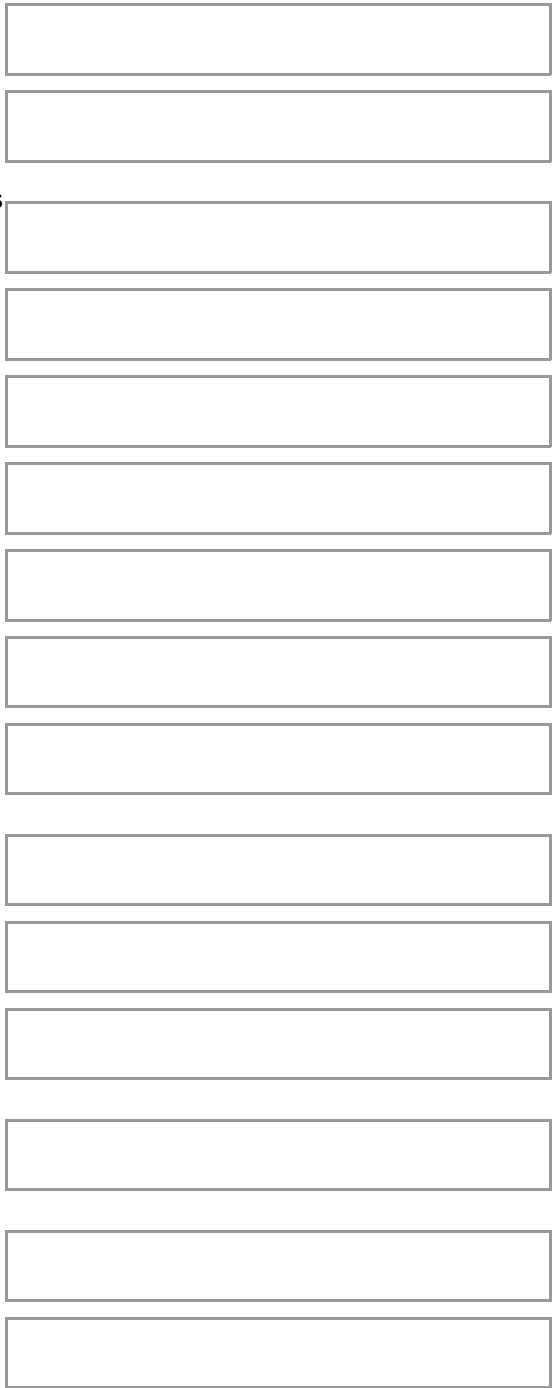


\section{Middle-stream, Niger}

Please give percentage weights to those services that you find to be most important in this sub-basin with the total adding to 100 .

Water for irrigated staples (e.g. rice, maize)

Water for irrigated cash crops (e.g. sugarcane)

Water for irrigated horticultural crops (e.g. vegetables fruits)

Water for fiber

Water for energy (e.g. hydropower)

Water for domestic water supply

Water for industrial water supply

Navigation

Fisheries/aquaculture

Environmental flows to maintain water-based ecosystems

Water for important cultural purposes

Water to support protected areas

Water to support nature and other items of religious and cultural significance

Water for wetland uses (e.g. aquatic species, regulation of floods, regulation of water quality)

Control of sedimentation and soil erosion
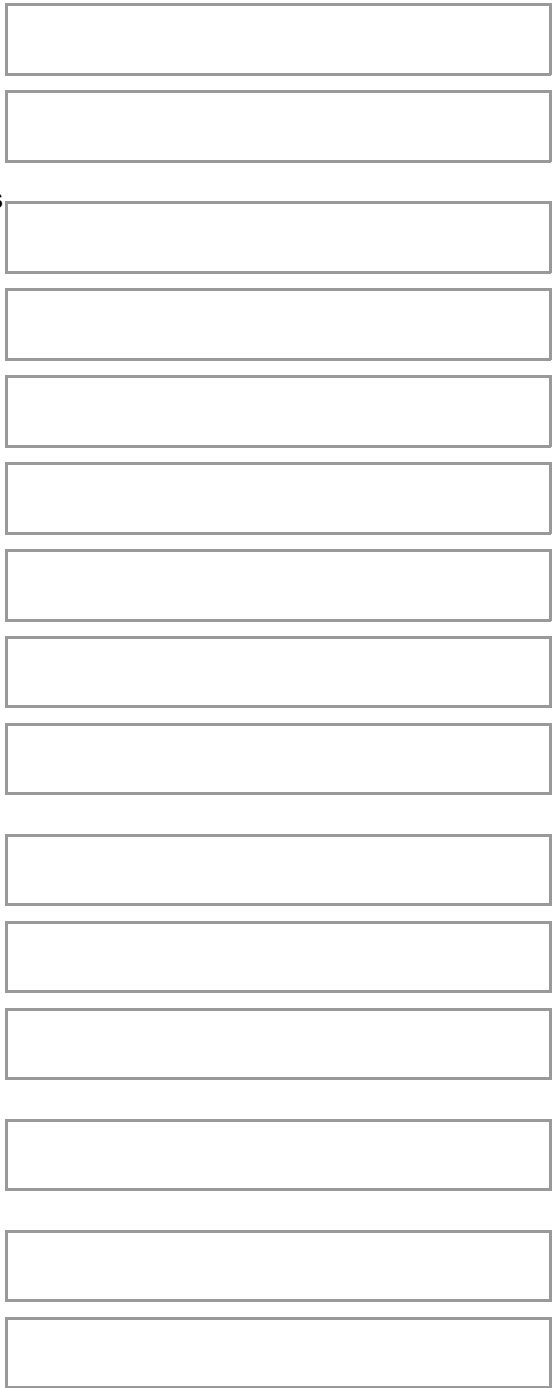


\section{Middle-stream, Nigeria}

Please give percentage weights to those services that you find to be most important in this sub-basin with the total adding to 100 .

Water for irrigated staples (e.g. rice, maize)

Water for irrigated cash crops (e.g. sugarcane)

Water for irrigated horticultural crops (e.g. vegetables fruits)

Water for fiber

Water for energy (e.g. hydropower)

Water for domestic water supply

Water for industrial water supply

Navigation

Fisheries/aquaculture

Environmental flows to maintain water-based ecosystems

Water for important cultural purposes

Water to support protected areas

Water to support nature and other items of religious and cultural significance

Water for wetland uses (e.g. aquatic species,

regulation of floods, regulation of water quality)

Control of sedimentation and soil erosion
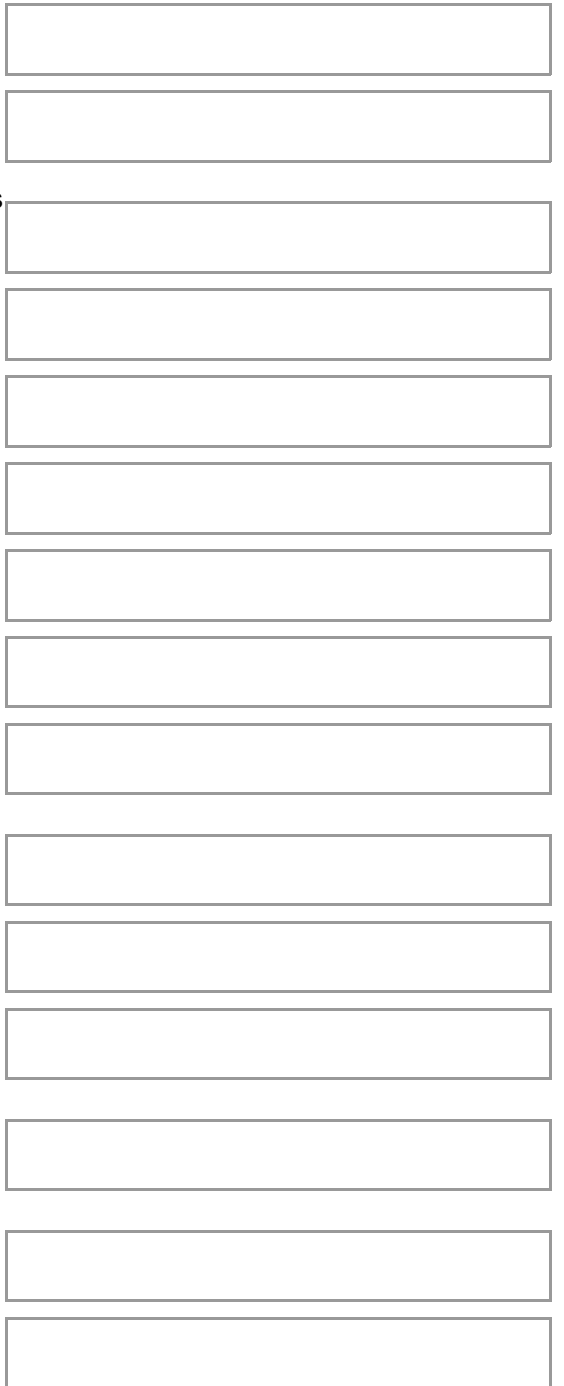


\section{Benue, Cameroon}

Please give percentage weights to those services that you find to be most important in this sub-basin with the total adding to 100 .

Water for irrigated staples (e.g. rice, maize)

Water for irrigated cash crops (e.g. sugarcane)

Water for irrigated horticultural crops (e.g. vegetables fruits)

Water for fiber

Water for energy (e.g. hydropower)

Water for domestic water supply

Water for industrial water supply

Navigation

Fisheries/aquaculture

Environmental flows to maintain water-based ecosystems

Water for important cultural purposes

Water to support protected areas

Water to support nature and other items of religious and cultural significance

Water for wetland uses (e.g. aquatic species,

regulation of floods, regulation of water quality)

Control of sedimentation and soil erosion
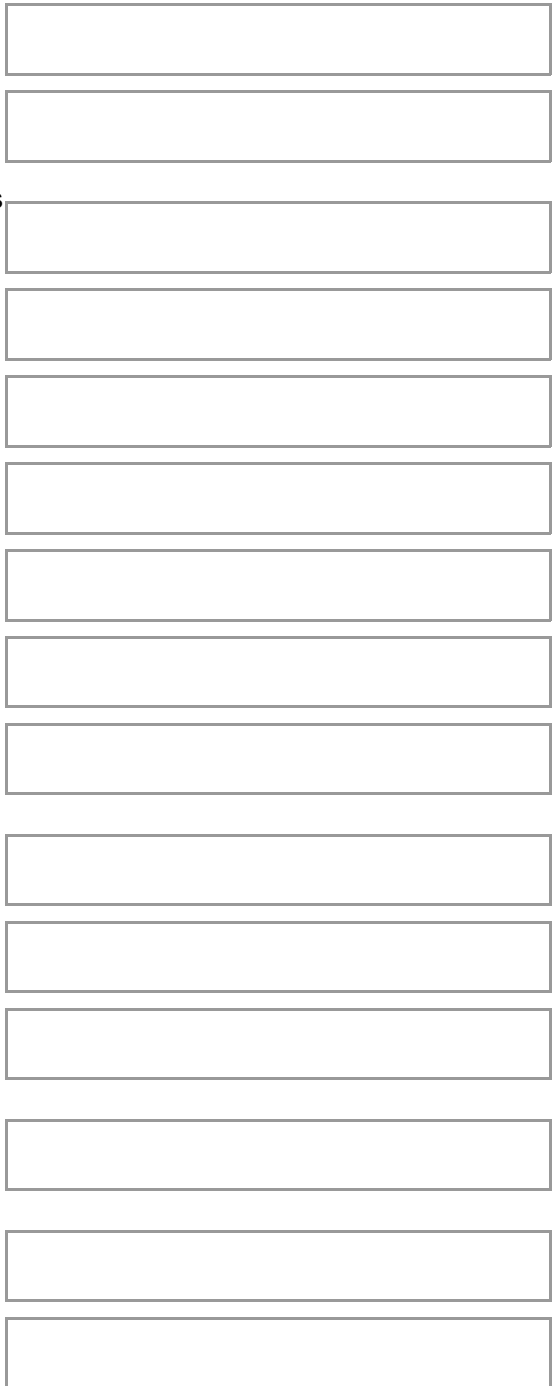


\section{Benue, Nigeria}

Please give percentage weights to those services that you find to be most important in this sub-basin with the total adding to 100 .

Water for irrigated staples (e.g. rice, maize)

Water for irrigated cash crops (e.g. sugarcane)

Water for irrigated horticultural crops (e.g. vegetables fruits)

Water for fiber

Water for energy (e.g. hydropower)

Water for domestic water supply

Water for industrial water supply

Navigation

Fisheries/aquaculture

Environmental flows to maintain water-based ecosystems

Water for important cultural purposes

Water to support protected areas

Water to support nature and other items of religious and cultural significance

Water for wetland uses (e.g. aquatic species,

regulation of floods, regulation of water quality)

Control of sedimentation and soil erosion
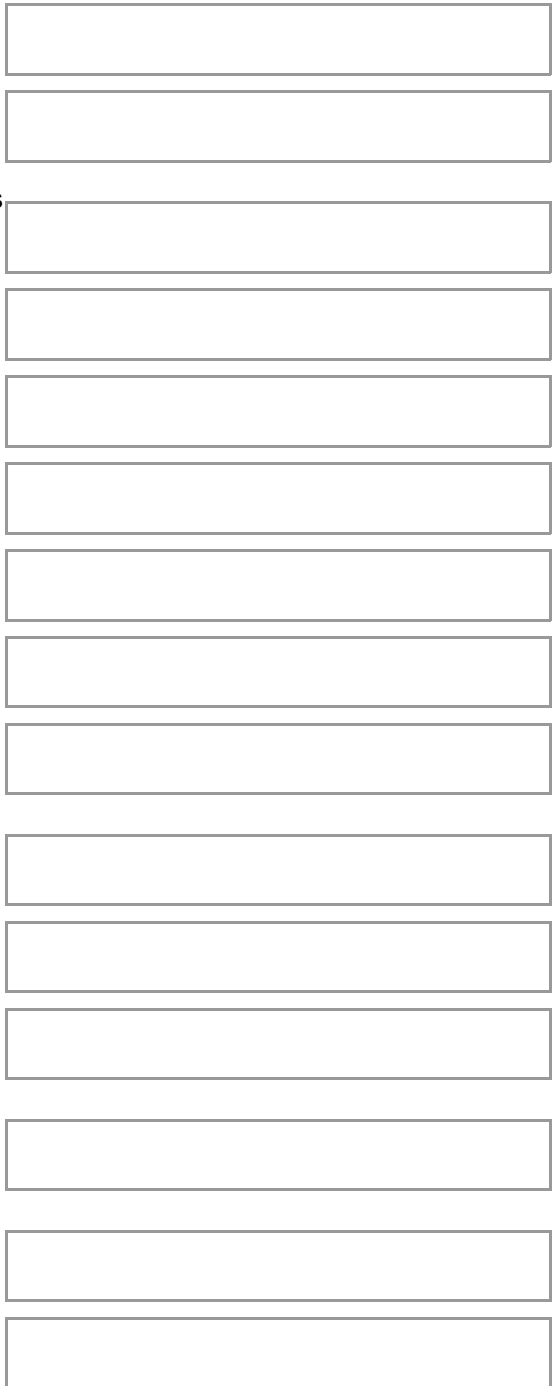


\section{Outlet Delta}

Please give percentage weights to those services that you find to be most important in this sub-basin with the total adding to 100 .

Water for irrigated staples (e.g. rice, maize)

Water for irrigated cash crops (e.g. sugarcane)

Water for irrigated horticultural crops (e.g. vegetables fruits)

Water for fiber

Water for energy (e.g. hydropower)

Water for domestic water supply

Water for industrial water supply

Navigation

Fisheries/aquaculture

Environmental flows to maintain water-based ecosystems

Water for important cultural purposes

Water to support protected areas

Water to support nature and other items of religious and cultural significance

Water for wetland uses (e.g. aquatic species, regulation of floods, regulation of water quality)

Control of sedimentation and soil erosion
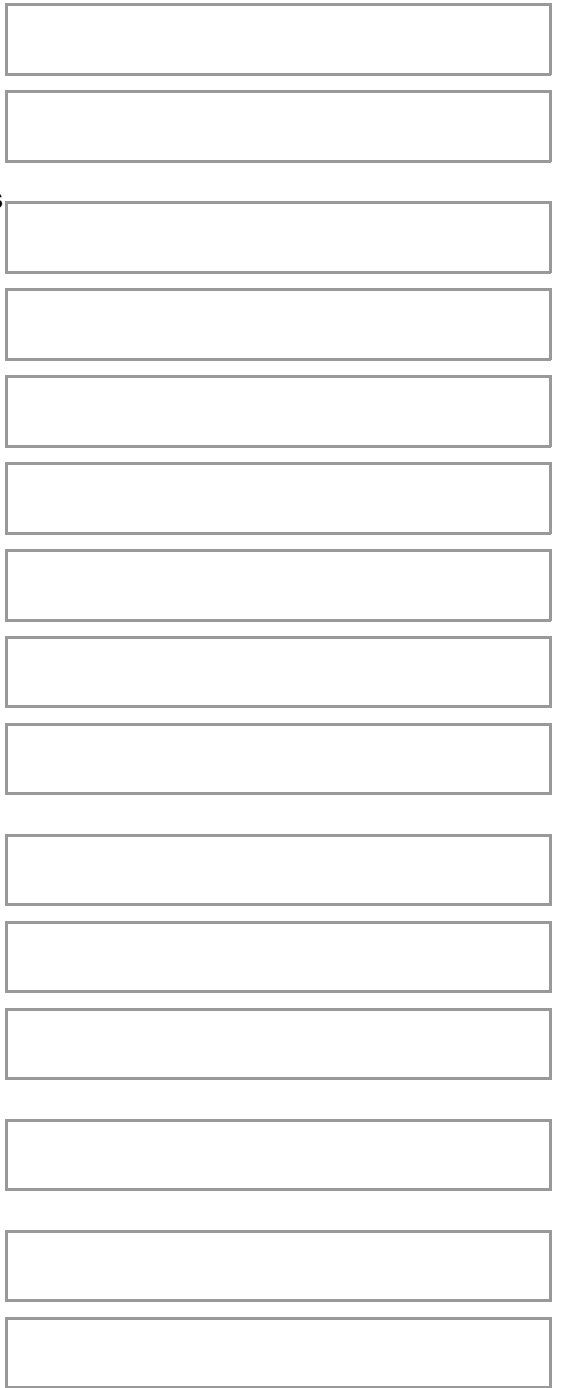

40. Are there any other ecosystem services that you believe are essential to the Niger River Basin that were not listed in the survey options?

Yes

No 


\section{River Basin Modeling for Ecosystem Services in the Niger}

\section{Additional Ecosystem Services}

41. Please list and briefly describe any additional important ecosystem services in the Niger and where they matter most. 


\section{River Basin Modeling for Ecosystem Services in the Niger}

Additional Comments on Ecosystem Service Modeling

42. Do you have any other comments or suggestions on water-related ecosystem service modeling for the Niger that we should consider? 


\section{River Basin Modeling for Ecosystem Services in the Niger}

43. Would you be willing to share your contact details?

Y Yes

No 


\section{River Basin Modeling for Ecosystem Services in the Niger}

\section{Contact Details}

44. Please provide your email.

45. Please provide your first and last name.

We thank you again for taking the time to answer this questionnaire. 


\section{S6 Overview, Design concepts, Details (ODD) protocol for the Agent-Based Model}

\section{Purpose}

The coupled modeling framework is used to simulate the impacts of water resources management decisions on the food-water-energy-environment nexus (FWEE) at the watershed scale. Novel advancements offered in this framework are 1) the ability of agents to directly interact by requesting assistance from other agents based on their level of cooperation (LOC); 2) representing the "environment" by coupling with a process-based model.

\section{Entities, state variables, and scales}

This model is composed of different agents. The river basin is divided into politically and hydrologically similar sub-regions, where water management is primarily carried under the ambit of a single administrative unit, which represents an autonomous agent. The coupled modeling framework consists of a hydrologic model and an agent-based model.

The hydrologic model operates on a daily time step, for a period of approximately 25 years for each case study presented. The spatial resolution for the hydrologic model is the HRU level for each sub-basin in a larger river basin. Each sub-basin is delineated into eight HRUs. The agentbased model operates on an annual time step, with the spatial scale dependent on the area of the country-basin that the agent represents.

The state variables in the model include streamflow at each sub-basin's outlet, the irrigated area for each crop in each sub-basin, the reservoir storage and releases.

\section{Process overview and scheduling}

The model begins by initializing the daily hydrologic model and running it for a four-year spinup period. The state variables from the hydrologic model on the last day of year 4 (streamflow at each sub-basin outlet, crop area and crop yields, and reservoir storage and release) are fed into the agent-based model. The agents make decisions on water management (based on preferences and level of cooperation) on an annual time step, through

i) a change in the operation of the reservoirs in its domain, or

ii) a change in the amount of irrigated area in a sub-basin in its domain

State variables for the ABM are updated on an annual time step. The decisions of the agents are fed back into the hydrologic model (implemented simultaneously in the next time step). Time is modeled as discrete time steps in both the models.

\section{Design concepts}

Basic principles

The agents are following rule-based simulation principles in which pre-defined rules are setup to guide agent's behavior. The environment is following basic hydrologic principles, such as 
rainfall-runoff process, surface water and groundwater interaction and water balance. These two principles interact when an agent's decision affects and/or is affected by the hydrologic cycle.

\section{Emergence}

The key outputs from the model include crop production, hydropower generation and ecological health for each agent. The preferences that agents have for different water uses influence the outcome for the particular water use. The willingness to cooperate of agents also affects the annual benefits derived by agents, in terms of direct and indirect (third party) impacts. These outcomes vary in a complex and stochastic manner depending on the agent characteristics.

\section{Adaptation}

Our algorithm models the interaction between the ABM and the hydrologic model and the process through which various agents make their water management decisions, in two distinct parts. In the first part, the agent's water management decision is made based on its preferences of water use, while in the second part the decisions are made based on its willingness to cooperate. In the first part, the algorithm uses the water use preferences for each agent, and compares the target value with the output from the SWAT model for each of the water uses to make the water management decision for each agent. Under the current setting, the agent is allowed to only make one water management decision every year.

For instance, consider an agent that ranks agricultural production higher than other water uses. In this case, the ABM checks to see whether crop production meets the target crop production. If crop production is significantly lower than the target crop production, then the agent decides to increase the irrigated area. If crop production meets the target production, then the ABM checks to see if hydropower generation for the current time step meets the hydropower generation target. If the hydropower generation target is not met, the agent decides to decrease the number of days to reach target storage. This allows for greater releases and increased hydropower generation. If the hydropower generation target has also been satisfied, then the ABM moves to the second part of the decision-making algorithm.

For each ecosystem hot spot, relevant Indicators of Hydrologic Alteration (IHA) and Environmental Flow Component (EFC) parameters are selected based on expert opinion to measure ecosystem health (Richter et al., 1997, 1996). Baseline values for relevant IHA and EFC are calculated from daily streamflow of the calibrated SWAT model. We use $\pm 10 \%$ from the baseline value as a decision threshold in the ABM as recommended by research consortium partner WorldFish. This means the modeled IHA and EFC values deviating from the baseline value by more than $10 \%$ would require an agent to take action. In the absence of detailed information on ecological needs, we incorporate ecosystem hotspot management in the model by creating a "flag" when the timing and magnitude of relevant IHA and EFC deviates from the target values in each hotspot. Thus, while the agents do not actively consider ecosystem hotspots in their decisions, they recognize when violations (deviation from target values) occur. We use these violations to constrain the agent's decision, so that if any of the ecologic targets have been violated and ecologic needs are ranked highest, no action can be undertaken for agricultural production or hydropower generation.

In the second part of the decision-making algorithm, the agents decide whether to alter their water management actions based on requests by downstream agents. This feature aims to 
represent the possibility of cooperative water management in a transboundary river basin. A downstream agent can request an upstream agent to change its reservoir operations to alleviate prolonged water scarcity (at least two time steps). For instance, if a downstream agent has been unable to meet its agricultural production target for two years, then it can request an upstream agent to increase releases. Wherever available, one upstream reservoir is identified for each agent.

Once a request is made by a downstream agent, the upstream agent first checks to see if it has surplus storage, after accounting for its own needs, to consider releasing additional water. If the available storage is not sufficiently higher than the target storage, then the upstream agent declines the request and does not change its reservoir operations. If the upstream reservoir has sufficient storage, then it decides whether to respond favorably to the downstream request based on its willingness to cooperate. In this modeling framework, the LOC represents the probability (from 0 to 1 ) of the agent to respond favorably to a downstream request and incorporates human decision making uncertainty, making the second part of the decision-making algorithm stochastic to mimic human decision uncertainty. In any given time step, an upstream reservoir can only respond to one request. Once the second part of the algorithm is executed, the water management decisions are made and relevant information is then fed back the SWAT model as inputs for the next time step.

\section{Objectives}

Agents make water management decisions, on an annual time step, for agricultural production, hydropower generation and ecological management relative to targets set using long-term historical data. Targets are defined for each of the three water uses based on historical flow conditions. The model algorithm compares the target value with the simulated values for each of the water uses and makes the management decision based on the water use preferences for each agent.

\section{Learning}

While the model structure allows for agents' preferences to vary, the current framework operates under constant agent preferences that do not change with time.

\section{Prediction}

Agents are assumed to be myopic, where they make water management decisions to satisfy the targets for the current time step. For instance, if needed the agent alters its reservoir operation to increase releases to increase hydropower generation in the current time step. However, this reduces the reservoir volume for the next time step and may lead to reduced production in the next time step. The agent does not consider these future impacts in its decision-making.

\section{Sensing}

The level of cooperation (LOC) signal is intentionally sent from downstream to upstream agents. Upstream agent will take this signal into their decisions and the structure is imposed. The environmental state valuables that each agent will sense for their decisions are last year's local crop production, hydropower generation and ecosystem health violation. 


\section{Interaction}

Agents interact both directly and indirectly. Agents interact indirectly through their water usage decisions. Agents interact directly through the level of cooperation parameter, where they can request an agent to change its water management decision to benefit downstream neighbors.

\section{Stochasticity}

Stochasticity is included in the agent-based model in terms of the agent's response to a request by another agent to change its reservoir operation. The model includes a parameter call level of cooperation (LOC) which represents the probability (from 0 to 1 ) of the agent to respond favorably to a downstream request and incorporates human decision making uncertainty.

\section{Collectives}

In the river basins used as case studies for this modeling framework, each individual agent is a member of the River Basin Authority (e.g. for the Mekong, this would be the Mekong River Commission). In some cases, it is also possible for two or more agents to belong to the same country. Collectives in the model are represented by agents' preferences for water usage that are based on surveys of water practitioners in that region. As such, it is an emergent property of the individuals within an agent. The modeling framework allows the user to define the collective behavior as they see appropriate.

\section{Observation}

For each agent, the level of crop production, reservoir storage and releases and indicators of ecological health for critical regions are saved and analyzed. All the output data following the hydrologic model spin-up period is used.

\section{Initialization}

At $\mathrm{t}=0$, the hydrologic model is initialized using historical climate and land cover data. The model is run for 4 time steps, as a spin-up period. The state variables from the hydrologic model at the end of $t=4$ are input into the agent-based model. The number of agents in the model remains the same throughout the simulation period. The initialization is always the same among all simulations. The state variables are set based on long-term averages corresponding to the period of analysis (e.g. crop yields). Sources for these datasets are provided in the table below.

SWAT is a semi-distributed model. In model setup, the Mekong River Basin is partitioned into 289 subbasins (Fig. S1(a)), and the Niger River Basin is divided into 178 subbasins (Fig. S1(b)). Hydrological response units (HRUs) were defined within subbasins to reflect the spatial variability of land use/land cover and soil. For this study, we defined crop HRUs for rainfed and irrigated upland crops and rice. The initial size of crop HRUs was estimated using cropping area data from International Food Policy Research Institute (IFPRI)'s SPAM database (You et al., 2014), which disaggregates national/sub-national crop production stations to a 5 arc minute grid.

\begin{tabular}{ll}
\hline Category & \multicolumn{1}{c}{ Data } \\
\hline Elevation & HydroSHEDS $^{1}$ \\
\hline Land use/land cover & GLC2000 $^{2}$ SPAM 2005 \\
\hline Soil & Soil Map of the World \\
\hline
\end{tabular}




\begin{tabular}{ll}
\hline Precipitation & $\begin{array}{l}\text { Mekong: APHRODITE } \\
\text { Niger: NCEP-CFSR }\end{array}$ \\
& using monthly precipitation data in CRU TS v. $4.00^{7}$ ) \\
\hline $\begin{array}{l}\text { Temperatures/solar radiation/relative } \\
\text { humidity/wind speed }\end{array}$ & NCEP-CFSR \\
\hline
\end{tabular}

1. Source: The SHuttle Elevation Derivatives at multiple Scales (HydroSHEDS) database http://www.hydrosheds.org/

2. Source: Global Land Cover (GLC) 2000 database. European Commission, Joint Research Centre. http://forobs.jrc.ec.europa.eu/products/glc2000/glc2000.php

3. Source: Spatial Production Allocation Model (SPAM) database for 2005, IFPRI. http://mapspam.info/

4. Source: FAO/UNESCO. http://www.fao.org/soils-portal/soil-survey/soil-maps-anddatabases/faounesco-soil-map-of-the-world/en/

5. Source: Asian Precipitation-Highly Resolved Observational Data Integration Towards the Evaluation of Water Resources (APHRODITE) project. http://www.chikyu.ac.jp/precip/english/conditions.html

6. Source: National Centers for Environmental Prediction (NCEP) Climate Forecast System Reanalysis (CFSR); downloaded via global weather database for SWAT https://globalweather.tamu.edu/

7. Source: Climatic Research Unit - University of East Anglia. http://www.cru.uea.ac.uk/data

\section{Input data}

The input data for this coupled model includes agent preferences of water use and level of cooperation. These agent specific values remain constant throughout the modeling run. Another input are the threshold values based on which agent's determine whether an outcome for water use is acceptable.

\section{Submodels}

We do not have submodels in this ABM. 


\section{S7 References}

Bagstad, K. J., Johnson, G. W., Voigt, B. and Villa, F.: Spatial dynamics of ecosystem service flows: A comprehensive approach to quantifying actual services, Ecosyst. Serv., 4, 117-125, doi:10.1016/j.ecoser.2012.07.012, 2013.

Barreteau, O., Bousquet, F., Millier, C. and Weber, J.: Suitability of Multi-Agent Simulations to study irrigated system viability: Application to case studies in the Senegal River Valley, Agric. Syst., 80(3), 255-275, doi:10.1016/j.agsy.2003.07.005, 2004.

Berger, T., Birner, R., Diaz, J., McCarthy, N. and Wittmer, H.: Capturing the complexity of water uses and water users within a multi-agent framework, Integr. Assess. Water Resour. Glob. Chang. A North-South Anal., 129-148, doi:10.1007/978-1-4020-5591-1-9, 2007.

Brady, M., Sahrbacher, C., Kellermann, K. and Happe, K.: An agent-based approach to modeling impacts of agricultural policy on land use, biodiversity and ecosystem services, Landsc. Ecol., 27(9), 1363-1381, doi:10.1007/s10980-012-9787-3, 2012.

Farolfi, S., Müller, J. P. and Bonté, B.: An iterative construction of multi-agent models to represent water supply and demand dynamics at the catchment level, Environ. Model. Softw., 25(10), 1130-1148, doi:10.1016/j.envsoft.2010.03.018, 2010.

Giacomoni, M. H., Kanta, L. and Zechman, E. M.: Complex Adaptive Systems Approach to Simulate the Sustainability of Water Resources and Urbanization, J. Water Resour. Plan. Manag., 139(5), 554-564, doi:10.1061/(ASCE)WR.1943-5452.0000302, 2013.

Giuliani, M. and Castelletti, A.: Assessing the value of cooperation and information exchange in large water resources systems by agent-based optimization, Water Resour. Res., 49(7), 39123926, doi:10.1002/wrcr.20287, 2013.

Giuliani, M., Castelletti, A., Amigoni, F. and Cai, X.: Multiagent Systems and Distributed Constraint Reasoning for Regulatory Mechanism Design in Water Management, J. Water Resour. Plan. Manag., 141(4), 4014068, doi:10.1061/(ASCE)WR.1943-5452.0000463, 2015.

Jeuland, M., Baker, J., Bartlett, R. and Lacombe, G.: The costs of uncoordinated infrastructure management in multi-reservoir river basins, Environ. Res. Lett., 9(10), 105006, doi:10.1088/1748-9326/9/10/105006, 2014.

Kanta, L. and Zechman, E.: Complex Adaptive Systems Framework to Assess Supply-Side and Demand-Side Management for Urban Water Resources, J. Water Resour. Plan. Manag., 140(January), 75-85, doi:10.1061/(ASCE)WR.1943-5452.0000301., 2014.

Kirby, J.M., Mainuddin, M., Podger, G. and Zhang, S., 2006. Basin water use accounting method with application to the Mekong Basin. Proceedings on the International Symposium on Managing Water Supply for Growing Demand, Bangkok, Thailand, 16-20 October 2006, Jakarta. Jakarta, Bangkok: UNESCO

Manley. 2015. http://www.climatedata.info/discussions/blogger/index.php/index.php?categories=Model

Miller, M. L., Ringelman, K. M., Schank, J. C. and Eadie, J. M.: SWAMP: An agent-based model for wetland and waterfowl conservation management, Simulation, 90(1), 52-68, 
doi:10.1177/0037549713511864, 2014.

Ng, T. L., Eheart, J. W., Cai, X. and Braden, J. B.: An agent-based model of farmer decisionmaking and water quality impacts at the watershed scale under markets for carbon allowances and a second-generation biofuel crop, Water Resour. Res., 47(9), 1-17, doi:10.1029/2011WR010399, 2011.

Schlüter, M., Leslie, H. and Levin, S.: Managing water-use trade-offs in a semi-arid river delta to sustain multiple ecosystem services: A modeling approach, Ecol. Res., 24(3), 491-503, doi:10.1007/s11284-008-0576-z, 2009.

Schwarz, N. and Ernst, A.: Agent-based modeling of the diffusion of environmental innovations - An empirical approach, Technol. Forecast. Soc. Change, 76(4), 497-511, doi:10.1016/j.techfore.2008.03.024, 2009.

Sun, Z. and Muller, D.: A framework for modeling payments for ecosystem services with agentbased models, Bayesian belief networks and opinion dynamics models, Environ. Model. Softw., 45(7), 15-28, doi:http://dx.doi.org/10.1016/j.envsoft.2012.06.007, 2013.

Thompson, J.R., Crawley, A. and Kingston, D.G., 2016. GCM-related uncertainty for river flows and inundation under climate change: the Inner Niger Delta. Hydrological Sciences Journal, 61(13), pp.2325-2347.

Yang, Y. C. E., Cai, X., Stipanović, D. M. and Stipanovic, D. M.: A decentralized optimization algorithm for multiagent system-based watershed management, Water Resour. Res., 45(8), 1-18, doi:10.1029/2008WR007634, 2009.

Yang, Y. E., Zhao, J., Cai, X. and Asce, M.: Decentralized optimization method for water allocation management in the Yellow River basin, J. Water Resour. Plan. Manag., 138(August), 313-325, doi:10.1061/(ASCE)WR.1943-5452.0000199., 2011.

You, L., U. Wood-Sichra, S. Fritz, Z. Guo, L. See, and J. Koo. 2014. Spatial Production Allocation Model (SPAM) 2005 v2.0. 